\title{
Atmospheric and Oceanic Conditions Associated with Southern Australian Heat Waves: A CMIP5 Analysis
}

\author{
AriaAn Purich, Tim Cowan, Wenju Cai, And Peter van Rensch \\ CSIRO Marine and Atmospheric Research, Aspendale, Victoria, Australia \\ PETTERI UOTILA \\ CSIRO Marine and Atmospheric Research, Aspendale, Victoria, Australia, and Finnish \\ Meteorological Institute, Helsinki, Finland
}

AleXandre Pezza And Ghyslaine Boschat

School of Earth Sciences, University of Melbourne, Parkville, Victoria, Australia

SARAH PERKINS

Centre of Excellence for Climate System Science, the University of New South Wales, Sydney, New South Wales, Australia

(Manuscript received 30 January 2014, in final form 14 July 2014)

\begin{abstract}
Atmospheric and oceanic conditions associated with southern Australian heat waves are examined using phase 5 of the Coupled Model Intercomparison Project (CMIP5) models. Accompanying work analyzing modeled heat wave statistics for Australia finds substantial increases in the frequency, duration, and temperature of heat waves by the end of the twenty-first century. This study assesses the ability of CMIP5 models to simulate the synoptic and oceanic conditions associated with southern Australian heat waves, and examines how the classical atmospheric setup associated with heat waves is projected to change in response to mean-state warming. To achieve this, near-surface temperature, mean sea level pressure, and sea surface temperature (SST) from the historical and high-emission simulations are analyzed. CMIP5 models are found to represent the synoptic setup associated with heat waves well, despite showing greater variation in simulating SST anomalies. The models project a weakening of the pressure couplet associated with future southern Australian heat waves, suggesting that even a non-classical synoptic setup is able to generate more frequent heat waves in a warmer world. A future poleward shift and strengthening of heat wave-inducing anticyclones is confirmed using a tracking scheme applied to model projections. Model consensus implies that while anticyclones associated with the hottest future southern Australian heat waves will be more intense and originate farther poleward, a greater proportion of heat waves occur in association with a weaker synoptic setup that, when combined with warmer mean-state temperatures, gives rise to more future heat waves.
\end{abstract}

\section{Introduction}

The semiarid and temperate regions of southern Australia are strongly influenced by large-scale climate

Corresponding author address: Ariaan Purich, CSIRO Marine and Atmospheric Research, 107-121 Station St., Aspendale, Victoria, 3195, Australia.

E-mail: ariaan.purich@csiro.au variability associated with tropical and extratropical climate modes (e.g., Cai et al. 2011a; Murphy and Timbal 2008). El Niño-Southern Oscillation, the Indian Ocean dipole, and the southern annular mode (SAM) often force variations in regional-scale climate and weather phenomena (Pui et al. 2012). Variations in the subtropical ridge (Cai et al. 2011b), blocking anticyclones (Cowan et al. 2013), and cutoff lows (Risbey et al. 2009) occur through the interaction of the atmosphere and the ocean 
on intraseasonal time scales, whereby heat is transported from the tropics to the extratropics.

For southeast Australia (SEA), persistent subtropical high pressure systems are often associated with the onset of northerly winds, which can lead to severe heat wave conditions (Pezza et al. 2012; Sadler et al. 2012; Marshall et al. 2014; Boschat et al. 2014). These were exemplified during the austral summer and autumn of 2013 (Bureau of Meteorology 2013). For southwest Australia (SWA), high pressure systems in the Great Australian Bight resulting in easterly winds can induce heat wave conditions (Pezza et al. 2012). These persistent highs are often referred to as blocking highs (Pezza et al. 2012), and we use this terminology throughout this manuscript. We note that such systems differ to those that occur farther south due to a split in the westerly jet $\left(\sim 50^{\circ} \mathrm{S}\right)$, which may also be referred to as blocking (Marshall et al. 2014).

Subtropical blocking events often act as a prelude to severe heat waves (Pezza et al. 2012) and are linked to the state of El Niño-Southern Oscillation, the Indian Ocean dipole, and the SAM. However, the relationships are highly dependent on seasonal and intraseasonal variations (Cowan et al. 2013; Wheeler et al. 2009), as well as on tropical heating and land temperatures (Ummenhofer et al. 2013). Midlatitude baroclinic wave trains have been identified as dominant during SEA heat waves (Boschat et al. 2014), although recent research also suggests that tropical cyclones can reinforce and strengthen blocking highs and their mobility, through their influence on Rossby waves (Parker et al. 2013).

Local and remote oceanic conditions have also been identified as factors contributing to heat wave development. Pezza et al. (2012) explored the association of SSTs in the lead up to heat waves for Melbourne and Perth, and found that subtropical (extratropical) Indian Ocean warming (cooling) enhances baroclinicity. This aids the development of Rossby wave trains that feed atmospheric blocking events. Tasman Sea cooling, warming across the $\sim 60^{\circ} \mathrm{S}$ latitude band in the southern Indian Ocean, and warm coastal SSTs in the Great Australian Bight have also been found to contribute to the onset of SEA summer heat waves (Sadler et al. 2012; Boschat et al. 2014).

Across Europe and the United States, heat waves are also typically associated with atmospheric blocking events, SST anomalies, and large-scale climate mode variability (e.g., Carril et al. 2008; Trenberth and Fasullo 2012; Lau and Nath 2012; Loikith and Broccoli 2014). For example, tropical SSTs and convection in the Atlantic Ocean are associated with Rossby wave train formation and downstream atmospheric blocking that lead to boreal summer heat waves across Europe and Russia (Della-Marta et al. 2007; Trenberth and Fasullo 2012;
Cassou et al. 2005). SSTs in the Mediterranean and Black Seas have also been shown to be closely correlated with eastern European heat waves, as they reinforce upper-level anticyclonic flow (Unal et al. 2013).

As heat waves across the globe are getting hotter, longer, and more frequent (e.g., Perkins et al. 2012), it is of great interest to sectors such as agriculture and health services to understand the future risk that increases in heat waves will have on communities (Nairn and Fawcett 2013). Coupled climate models from phase 5 of the Coupled Model Intercomparison Project (CMIP5) capture the observed temporal and spatial increase in heat extremes globally (Coumou and Robinson 2013). In the twenty-first century these models project a further strong increase, even if strong mitigation efforts commence. Highly populated regions such as the western and central United States, Europe, and southern Australia will likely experience more frequent, longer, and hotter heat waves (Meehl and Tebaldi 2004; Mastrandrea et al. 2011; Lau and Nath 2012; Lewis and Karoly 2013; Cowan et al. 2014). However, only a limited number of studies (e.g., Lau and Nath 2012) have focused on the simulation of atmospheric and oceanic dynamics that contribute to severe heat wave events.

To date no study has focused on whether future increases in southern Australian heat waves (e.g., Cowan et al. 2014) can be linked to changes in atmospheric variability and SSTs. Using model simulations from the CMIP5 archive we investigate the observed and simulated atmospheric and oceanic conditions preceding and during heat wave events across southern Australia. We assess how well the models simulate heat wave conditions, and attempt to better understand whether dynamical processes play a role in the substantial increases in future heat waves.

\section{Data and methods}

\section{a. Heat wave definition}

We define southern Australian heat waves as austral summer (December-February) events only, as this is when they have the greatest impact on human health (McMichael et al. 2006) and are associated with natural disasters such as bush fires (Pezza et al. 2012). Following on from Cowan et al. (2014), heat waves are defined as a period of three or more consecutive days during which daily maximum temperature $\left(T_{\max }\right)$ exceeds a threshold temperature, and daily minimum temperature $\left(T_{\min }\right)$ also exceeds a threshold temperature on the second and third days (Pezza et al. 2012). This definition takes into account that heat waves have the most severe effect on human health when there is no relief between hot days, 


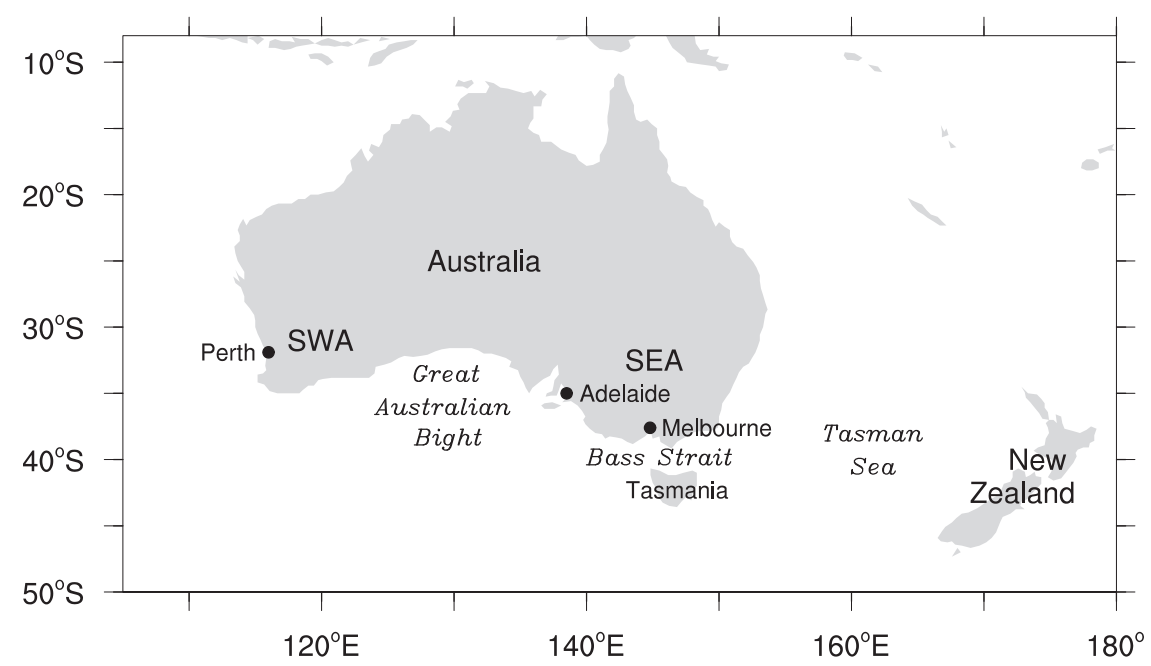

FIG. 1. The regions of focus: Southeast Australia (SEA) and southwest Australia (SWA) along with major cities within these regions and local oceanic features.

and is similar to previous studies (e.g., Della-Marta et al. 2007; Carril et al. 2008; Lau and Nath 2012). The $T_{\max }$ and $T_{\min }$ thresholds used here are the respective monthly 90th percentiles for the 1950-2005 climatology. As in Pezza et al. (2012), all days in a heat wave event are referenced to the monthly threshold temperatures for the first day of that heat wave.

Two regions of interest are focused on: SEA and SWA, shown in Fig. 1. Rather than averaging heat waves across multiple grid points in these regions, which can average out local heat wave events, we define heat waves for key cities in each region. Daily $T_{\max }$ and $T_{\min }$ are interpolated to the airport station locations for Melbourne $\left(37.6^{\circ} \mathrm{S}\right.$, $\left.144.8^{\circ} \mathrm{E}\right)$ and Adelaide $\left(35.0^{\circ} \mathrm{S}, 138.5^{\circ} \mathrm{E}\right)$ in SEA, and for Perth $\left(31.9^{\circ} \mathrm{S}, 116.0^{\circ} \mathrm{E}\right)$ in SWA. The observed and modeled dynamical setup prior to and during heat waves is found to be very similar for Melbourne and Adelaide (e.g., Fig. 2; see also Pezza et al. 2012), so we use Melbourne heat waves to represent heat waves across SEA.

The main metrics that describe heat wave frequency, duration, and amplitude have been well documented in Perkins and Alexander (2013). Their simulated historical characteristics and projected twenty-first-century increases across Australia are presented in Cowan et al. (2014). In this study we focus on documenting how well the models simulate atmospheric and oceanic conditions prior to and during heat waves, and how these may change in a warming climate.

\section{b. Observational and CMIP5 datasets}

As in Cowan et al. (2014), heat waves are investigated over the historical (December 1949-November 2005) and future (December 2005-November 2100) periods. For simplicity we refer to the year of a given summer based on the year of the January (i.e., the periods of analyses are 1950-2005 and 2006-2100).

CMIP5 daily $T_{\max }$ and $T_{\min }$ from 15 models (listed in Fig. 2; see expansions of model names in the appendix) for the historical and high-emission representative concentration pathway (RCP) 8.5 experiments are utilized to determine the dates of simulated heat wave events. Daily 850-hPa temperature $\left(T_{850}\right)$, mean sea level pressure (MSLP), 500-hPa geopotential height $\left(Z_{500}\right),{ }^{1}$ and SST data for the historical simulation, as well as MSLP data for the RCP8.5 simulation, are also analyzed.

For comparison, observed heat wave dates are determined using the Bureau of Meteorology gridded $\left(0.05^{\circ} \times 0.05^{\circ}\right)$ temperature dataset (Jones et al. 2009). Daily $T_{850}$, MSLP, and $Z_{500}$ are taken from the National Centers for Environmental Prediction (NCEP)National Center for Atmospheric Research (NCAR) reanalysis (Kalnay et al. 1996), as this reanalysis covers the full historical period assessed here (1950-2005). Similar results (not shown) are obtained using atmospheric data from 1) the 40-yr European Centre for Medium-Range Weather Forecasts (ECMWF) Re-Analysis (ERA-40; data available over 1958-2002; Uppala et al. 2005) and 2) the Interim ECMWF Re-Analysis (ERA-Interim; data available from January 1979 onward; Dee et al. 2011). Daily SST data are not available for the NCEP-NCAR reanalysis, so instead they are taken from ERA-Interim. Similar results (not shown) are obtained using daily SST

\footnotetext{
${ }^{1}$ The $T_{850}$ and $Z_{500}$ datasets begin in January 1950, except for CanESM2, GFDL-ESM2G, GFDL-ESM2M, HadGEM2-CC, and IPSL-CM5A-LR, which begin in December 1949; CSIRO Mk3.6.0 does not have $Z_{500}$ available.
} 

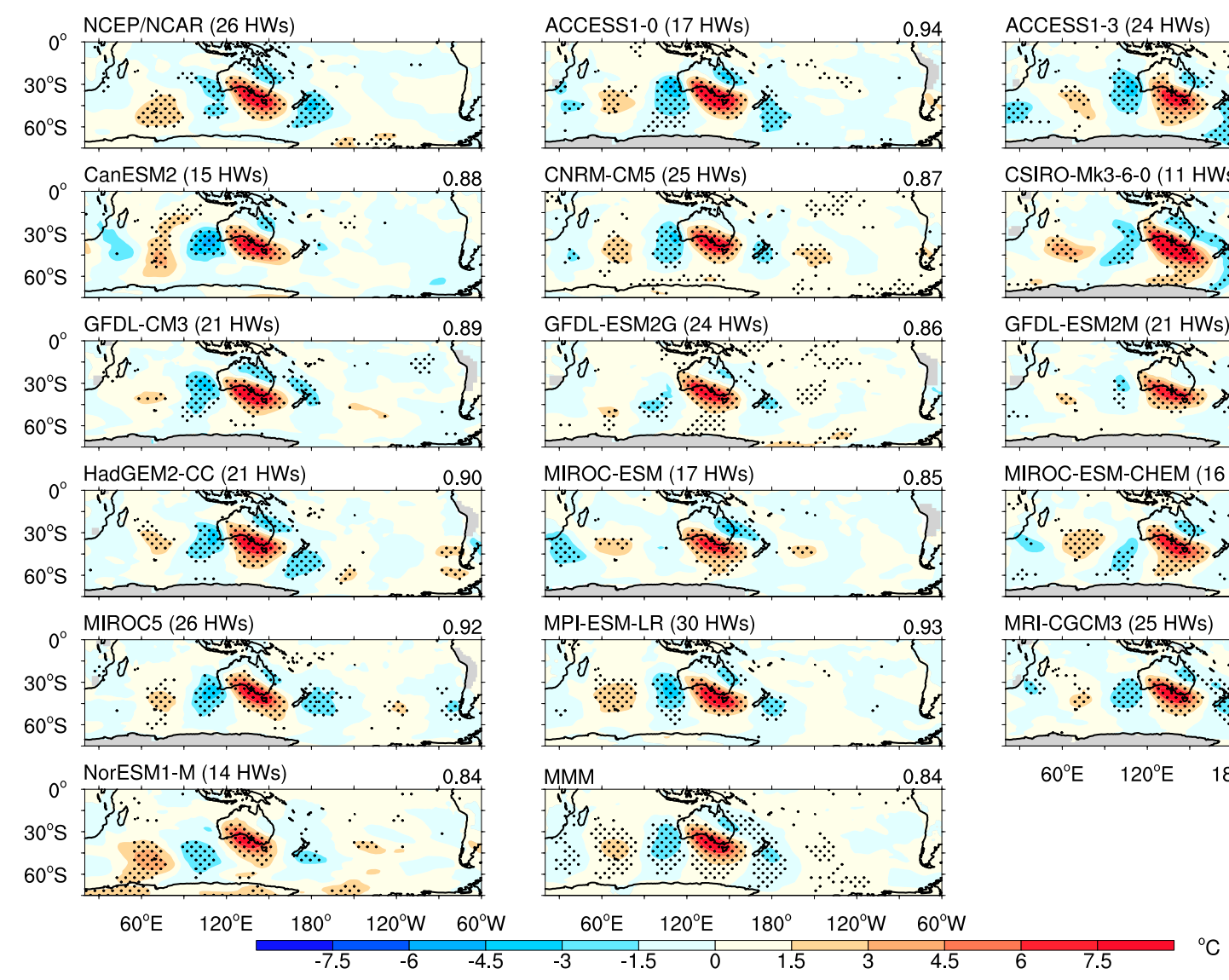

FIG. 2. Composites of $850-\mathrm{hPa}$ temperature anomalies $\left({ }^{\circ} \mathrm{C}\right)$ for the first day of heat waves in SEA for observations (top left panel) and CMIP5 models (see expansions of model names in the appendix) over 1950-2005. The multimodel mean (MMM) is also shown (bottom center panel). Anomalies are referenced to the 1950-2005 climatology. Statistical significance exceeding the two-tailed 95\% confidence level is shown with stippling. In the MMM, the stippling indicates where $\geq 80 \%$ of models agree on the sign of the MMM anomaly. The number of heat waves for observations and models is indicated above each panel on the left. The pattern correlation coefficient for each model compared to the observations is indicated above each panel on the right. Pattern correlations are calculated over $10^{\circ}-60^{\circ} \mathrm{S}$, $60^{\circ} \mathrm{E}-150^{\circ} \mathrm{W}$.

data from the National Oceanic and Atmospheric Administration (NOAA) v2 high-resolution blended analysis (data available from 1982 onward; Reynolds et al. 2002).

\section{c. Composites and anticyclone tracking scheme}

The dates of historical heat wave events are used to construct composites of $T_{850}$, MSLP, $Z_{500}$, and SST anomalies. All datasets are bilinearly interpolated to a standard $1^{\circ} \times 1^{\circ}$ grid. Statistical significance in composite maps is constructed through a $95 \%$ confidence level two-tailed $t$ test, which determines when the composite is distinguishable from the 1950-2005 climatological period (e.g., as in Ummenhofer et al. 2011). A multimodel mean (MMM) composite is also constructed. In the MMM, each model is weighted evenly, regardless of the number of heat wave events simulated. Statistical significance in the MMM is indicated where $\geq 80 \%$ of models agree on the sign of the MMM anomaly.

Pattern correlation coefficients are calculated between the observed composite and the composite of each model. For atmospheric fields, the domain over which correlations are calculated covers the dominant anomaly centers of the relevant wave train in the observations. For both SEA and SWA heat waves, wave trains begin in the southern Indian Ocean (where anomalies first become statistically significant). For SEA events, significant anomalies often extend east of New Zealand, but this is not the case for SWA events. Thus, for SEA composites, pattern correlation coefficients are calculated over $10^{\circ}-60^{\circ} \mathrm{S}, 60^{\circ} \mathrm{E}-150^{\circ} \mathrm{W}$. For 
SWA, they are calculated over $10^{\circ}-60^{\circ} \mathrm{S}, 60^{\circ} \mathrm{E}-180^{\circ}$. For SST, since both local and remote anomalies are of interest, pattern correlation coefficients are calculated over the shown domain: $0^{\circ}-75^{\circ} \mathrm{S}, 20^{\circ} \mathrm{E}-60^{\circ} \mathrm{W}$.

To track blocking high pressure systems associated with heat waves, we utilize the Melbourne University tracking scheme (Murray and Simmonds 1991). This tracking scheme is fully automatic and calculates the trajectories of anticyclones and statistics associated with their properties. The Melbourne University tracking scheme has been used previously for tracking cyclones and anticyclones associated with heat wave events (Pezza et al. 2012). A detailed description of this scheme and parameter values used can be found in Pezza and Ambrizzi (2003). Here we apply the tracking scheme to 13 of the 15 CMIP5 models ${ }^{2}$ that have 6-hourly MSLP data available.

The tracking scheme uses the Laplacian of pressure to find the point of maximum pressure in a closed anticyclone, where the pressure is higher than the surrounding eight points. For observations the minimum threshold for the Laplacian at the anticyclone center (the intensity or character of the anticyclone) is set to 0.2 , while the minimum threshold for the average Laplacian pressure of the surrounding eight points is set to 0.1 (Pezza and Ambrizzi 2003). The minimum thresholds used for observations are not used for CMIP5 models, to allow the tracking scheme to locate both well-defined anticyclones and open pressure ridges in model output. Each model is examined on its native grid, ranging from $1.1^{\circ} \times 1.1^{\circ}(\mathrm{MRI}-\mathrm{CGCM})$ to $2.8^{\circ} \times 2.8^{\circ}$ (CanESM2, MIROC-ESM, MIROC-ESMCHEM) resolution. Model resolution in the tracking scheme does not influence the anticyclone trajectories of interest given the lack of substantial land topography. We find that even models with the same grid resolution [e.g., Geophysical Fluid Dynamics Laboratory (GFDL) models] can display quite different anticyclone trajectories (not shown). Resolution becomes more important when examining systems closer to, for example, the Antarctic coastline (Uotila et al. 2009).

The scheme uses a procedure to estimate the position of the anticyclone back every $6 \mathrm{~h}$ and calculates the probability between the projected trajectory and actual track. We also analyze the positions of the anticyclones within their most likely locations for the first day of heat wave events [the Tasman Sea for SEA $\left(20^{\circ}-50^{\circ} \mathrm{S}, 140^{\circ}-\right.$ $190^{\circ} \mathrm{E}$ ), and the Great Australian Bight-eastern Indian Ocean for SWA $\left.\left(20^{\circ}-50^{\circ} \mathrm{S}, 80^{\circ}-150^{\circ} \mathrm{E}\right)\right]$. At each 6 -h

\footnotetext{
${ }^{2}$ HadGEM2-CC is excluded as its 360-day calendar is incompatible with the tracking scheme. NorESM1-M is excluded due to an eastward bias for both SEA and SWA anticyclones and possible orographic issues resulting in failure to track anticyclones.
}

interval this domain box is shifted westward or eastward to capture the anticyclone at the previous time step, which in turn is used as the center of a new search domain.

We track heat wave-inducing anticyclones back for a maximum of 10 days, when possible (i.e., not all tracks are 10 days long), to encompass the period where wave trains can be monitored (around 8 days for SEA but only 3 days for SWA; Pezza et al. 2012). For cases in which the anticyclone splits from a quasi-stationary ridge or does not have a closed center, the tracking scheme may not detect the center. In such cases, we move to the previous time step to locate the system upstream. This allows for continuity of the tracks, particularly across Bass Strait where the tracking scheme has difficulty locating anticyclones. If the tracking scheme does not detect a discrete high pressure center for two days, the track is ended.

\section{Historical heat wave climatologies}

The total number of austral summer heat waves for the observations and simulated by each model is shown for SEA in Fig. 2 and for SWA ${ }^{3}$ in Fig. 3. For SEA, 26 heat waves are observed over the 56-yr historical period. The models simulate 11-30 (mean of 20.5) events, on average underestimating the number of events per summer. The number of events is better simulated for SWA; 33 heat waves are observed and the models simulate 17-49 (mean of 31.1) events. Consistent with observations, the models simulate little change in the heat wave frequency across each region over 1950-2005 (Cowan et al. 2014). Based on the dates of heat wave events, composites of the atmospheric fields on the first day of each event and for SSTs in the week leading up to each event are presented.

\section{a. 850-hPa temperature composites}

Figures 2 and 3 show historical composites of daily $T_{850}$ anomalies from SEA and SWA heat waves, respectively. Spatial patterns in $T_{850}$ rather than surface temperature are assessed as they are less affected by small-scale surface processes. For SEA, a strong warm temperature anomaly is observed over southern SEA (Fig. 2, top left). This anomaly is elongated and tilted northwest to southeast, also covering Adelaide and Tasmania, and extending over the southern Tasman Sea. This demonstrates that the composite is representative of the large-scale conditions. The warm anomaly is

\footnotetext{
${ }^{3}$ As NorESM1-M simulates one SWA heat wave in December 1949 , the $T_{850}$ and $Z_{500}$ composites (which only have data available from January 1950 in this model) exclude this event, resulting in 42 events (compared to 43 for other variables).
} 

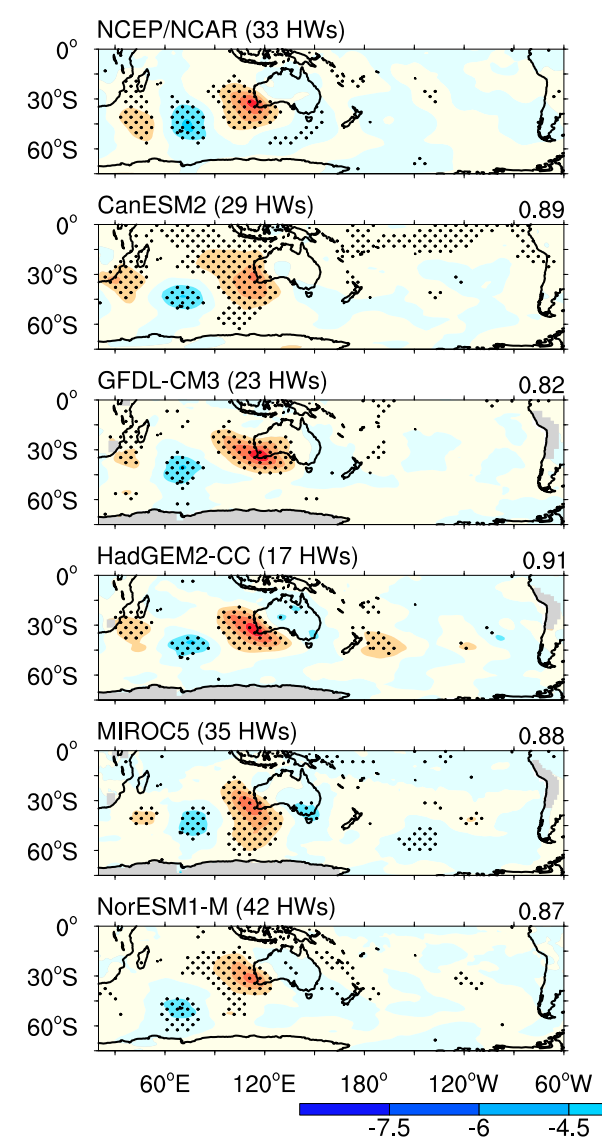
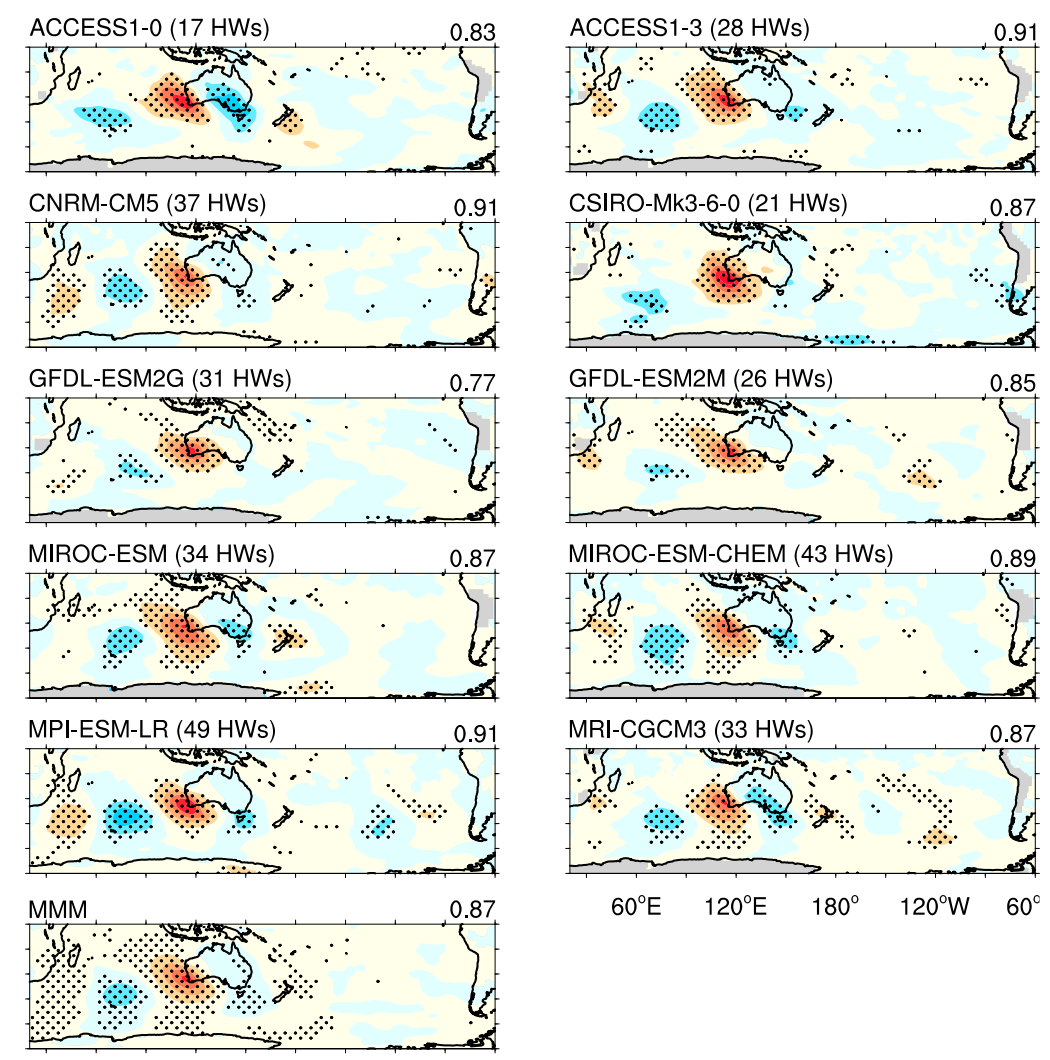

FIG. 3. As in Fig. 2, but for SWA. Pattern correlations are calculated over $10^{\circ}-60^{\circ} \mathrm{S}, 60^{\circ} \mathrm{E}-180^{\circ}$.

surrounded by three weaker cool anomalies to the west, north, and east. The models capture this pattern well, as demonstrated by the high pattern correlations exhibited by all models. Correlation coefficients range from 0.82 to 0.94 , with a median of 0.89 . All models exhibit a strong warm anomaly over SEA, with the elongated northwest-to-southeast tilt. Most models also simulate the $T_{850}$ wave train pattern, simulating both the weaker warm anomaly in the southern Indian Ocean $\left(\sim 80^{\circ} \mathrm{E}\right)$ and the cold anomaly just west of SWA, associated with the summer monsoon trough (Pezza et al. 2012).

The models also simulate the warm anomaly associated with SWA heat waves reasonably well. Based on visual inspection, there appears to be more variation than for the SEA $T_{850}$ anomaly. However, pattern correlation coefficients are almost as high, ranging from 0.77 to 0.91 , with a median of 0.87 . The observed warm anomaly is weaker in magnitude than that associated with SEA heat waves (cf. Figs. 2 and 3, top left panels) and the models accurately simulate this. A statistically significant cool anomaly southwest of the warm anomaly $\left(\sim 80^{\circ} \mathrm{E}\right)$ and another significant warm anomaly farther west $\left(\sim 40^{\circ} \mathrm{E}\right)$ are also observed. All of the models are able to simulate the cool anomaly to the southwest, and most also simulate the warm anomaly at $\sim 40^{\circ} \mathrm{E}$. In the observations a weak but significant cool anomaly south of Tasmania is also seen. Many models simulate this cool anomaly too far north (over the continent) and stronger in magnitude than observed.

The patterns of $T_{850}$ anomalies suggest that heat waves affecting SEA and SWA are confined to southern regions. During SEA heat waves $T_{850}$ anomalies do not extend north into central and eastern Australia. During SWA heat waves $T_{850}$ anomalies tend to be confined to the southwest, although some extend to the lower tropics (e.g., CanESM2, CSIRO Mk3.6.0). The anomalous temperature patterns also indicate that extratropical wave train activity is a key feature of heat waves in both SWA and SEA, as discussed next.

\section{b. MSLP composites}

Composites of daily MSLP are constructed to assess the surface atmospheric circulation conditions at the beginning of heat waves. Figure 4 shows the MSLP 
SEA first HW day MSLP' composites: 1950-2005 DJF
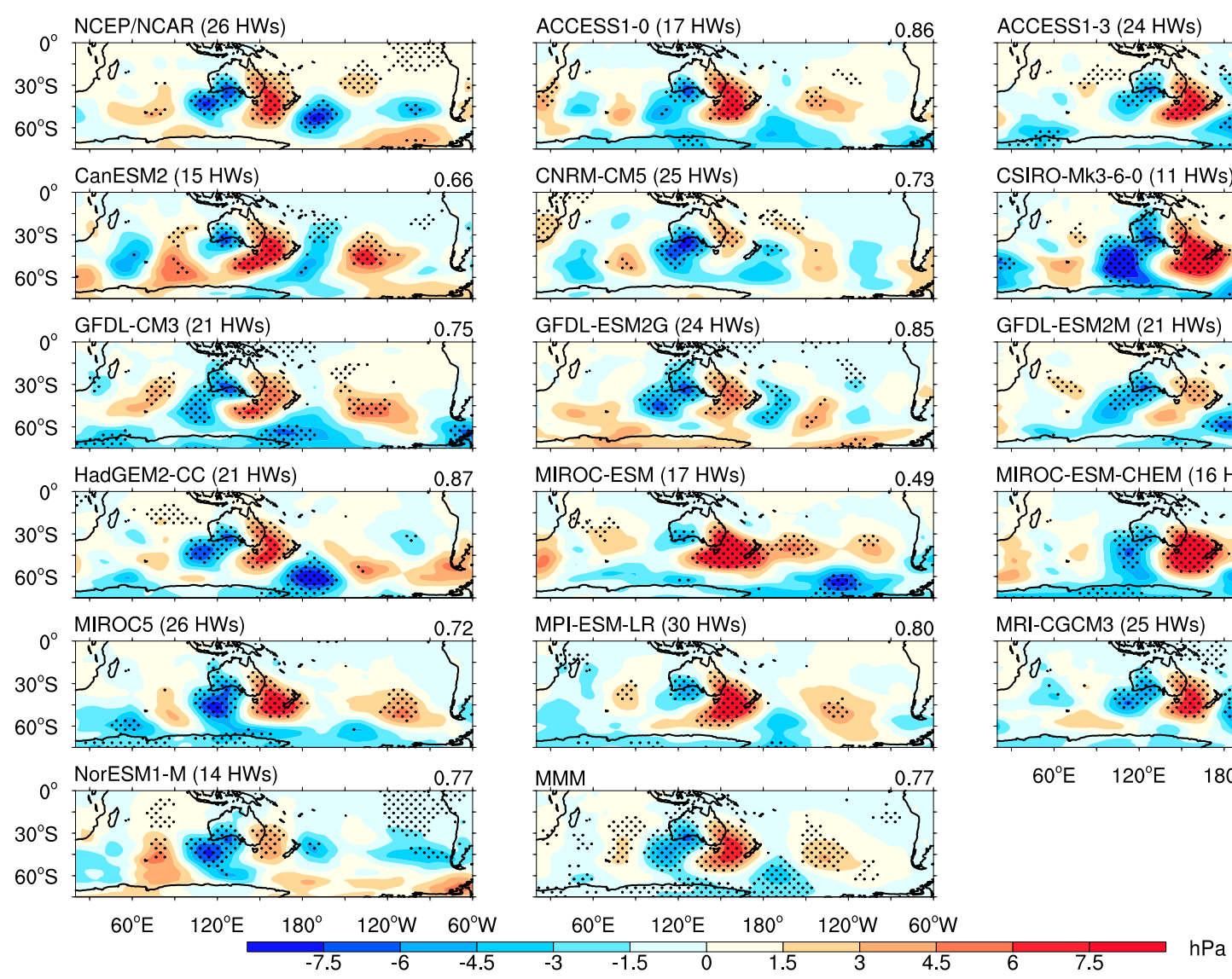

FIG. 4. As in Fig. 2, but for MSLP anomalies (hPa).

pattern at the start of SEA heat waves. All models simulate the pressure dipole that flanks SEA: a high pressure anomaly (blocking anticyclone) over the Tasman Sea, coupled with a low pressure anomaly (cyclone) stretching from southern Australia to SWA. In all cases, both centers of the dipole are statistically significant. The meridionally elongated shape of the anticyclone stretching from the tropics to the extratropics and the double-centered low are both well represented by the models. This setup allows northerly winds on the western (eastern) flank of the anomalous high (low) to direct warm, dry air from central Australia toward SEA (Pezza et al. 2012). However, there is some variation in the magnitude of the respective centers and their spatial distributions among the models. Pattern correlation coefficients are lower and more varied than for $T_{850}$, ranging from 0.49 to 0.88 , with a median of 0.75 .

Most models simulate the high-latitude Rossby wave train structure associated with heat waves, although they tend to show disagreement on the position of the weaker anticyclone to the west of the double-centered depression. There is no indication that the strength of the cyclone and anticyclone relates to the number of heat wave events simulated by the models. For example, CNRMCM5 simulates 25 events, despite simulating a weak and tropically biased blocking anticyclone. On the other hand, CSIRO Mk3.6.0 simulates strong pressure gradients but only 11 events. The tropical or poleward biases in the synoptic setup may be related to the position and strength of the near-surface westerly jet, with models such as MIROC-ESM and MIROC-ESMCHEM exhibiting a poleward bias in their subtropical jets (Bracegirdle et al. 2013). Recent research has also suggested that models that fully resolve the stratosphere are more likely to generate a mean austral summer subtropical jet that is farther equatorward (Wilcox et al. 2012), which may influence the position and strength of the synoptic systems passing south of Australia.

Figure 5 shows the anomalous MSLP composites for SWA. Heat waves are associated with an anticyclone over the Great Australian Bight directing anomalous warm easterlies from the interior toward SWA. Results shown in Pezza et al. (2012) over 1979-2008 suggest that the anticyclone forms part of a pressure ridge extending 
SWA first HW day MSLP' composites: 1950-2005 DJF
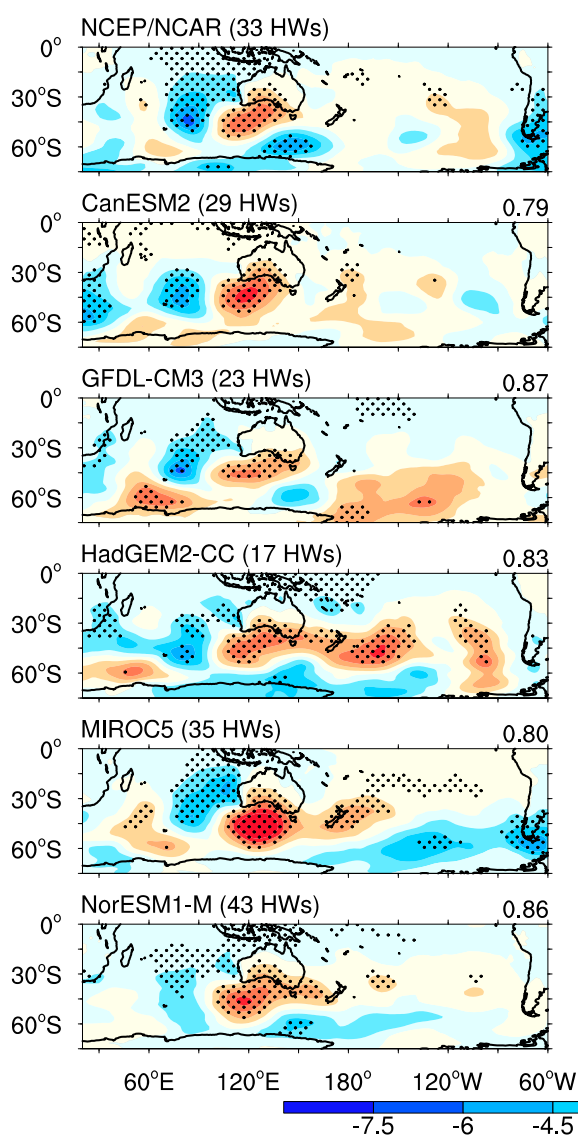
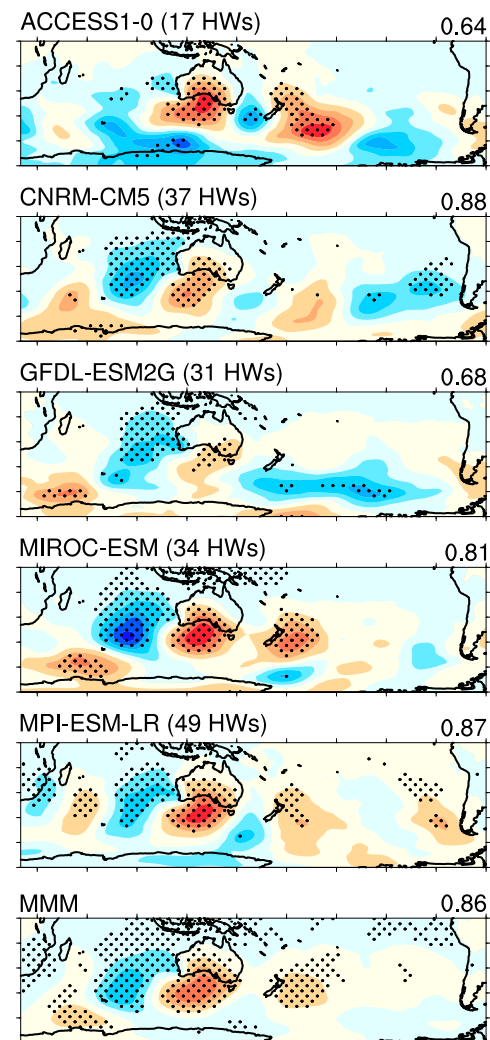

$60^{\circ} \mathrm{E} \quad 120^{\circ} \mathrm{E} \quad 180^{\circ} \quad 120^{\circ} \mathrm{W} \quad 60^{\circ} \mathrm{W}$

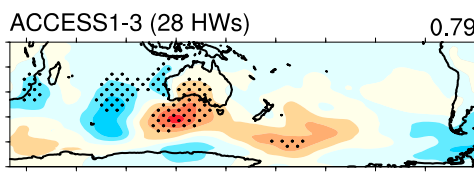

CSIRO-Mk3-6-0 (21 HWs)

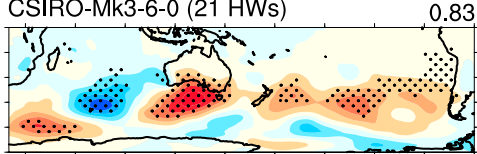

GFDL-ESM2M (26 HWs)

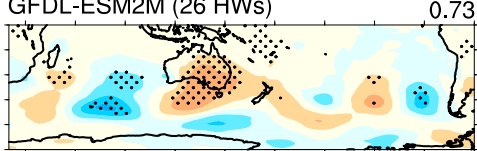

MIROC-ESM-CHEM (44 HWs)
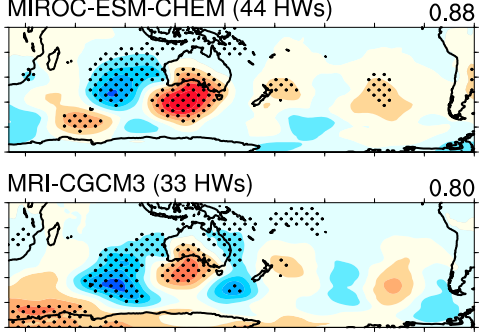

$60^{\circ} \mathrm{E}$

FIG. 5. As in Fig. 4, but for SWA. Pattern correlations are calculated over $10^{\circ}-60^{\circ} \mathrm{S}, 60^{\circ} \mathrm{E}-180^{\circ}$.

into the southern Indian Ocean. In this analysis over 1950-2005, the ridge is straddled by a broad depression at $\sim 80^{\circ} \mathrm{E}$. The models generally simulate the position and shape of the high pressure system well, with the center statistically significant in all models. It is noted that ACCESS 1.3, CSIRO Mk3.6.0, and HadGEM2-CC simulate the anticyclone as part of a broader midlatitude high pressure ridge that stretches well into the South Pacific Ocean, as in the observations shown in Pezza et al. (2012). An anomalous cyclone is observed over the southern Indian Ocean, the simulation of which varies among models (e.g., ACCESS 1.0 simulates a weaker upstream cyclone). Nevertheless, because all models capture the anticyclone and some form of an upstream cyclone, pattern correlations are somewhat higher than for SEA. Correlation coefficients range from 0.64 to 0.88 , with a median of 0.81 . Many models and the MMM also show an overly strong anticyclone east of New Zealand.

In summary, the models show a broad consensus ( $\geq 80 \%$ model agreement in the MMM) on the MSLP conditions of SEA heat waves. All models simulate the eastward propagating high-latitude wave train with a zonal dipole over southern Australia, directing warm air over SEA. For SWA heat waves, all models simulate the anticyclone to the south of Australia. However, they show less agreement on the surrounding synoptic conditions, with patterns ranging from a positive regional SAM to strong wave train activity. To investigate the baroclinic nature of the setup, we now assess $Z_{500}$.

\section{c. 500-hPa geopotential height composites}

Figure 6 shows the $Z_{500}$ anomalies for SEA heat waves. As with MSLP, the models capture the observed midlevel pattern of anomaly centers, most being statistically significant compared to the climatology. Pattern correlation coefficients are higher than for MSLP, ranging from 0.60 to 0.92 , with a median of 0.86 . The wave train structure is evident in all models, although the spatial extent and intensity of the cyclonic centers on either flank of the anticyclone varies. The vertical tilt of the Tasman Sea anticyclone is also evident, with $Z_{500}$ anomalies westward of MSLP counterparts (cf. Fig. 4, where the anticyclone is centered over the Tasman Sea, 
SEA first HW day 500-hPa Z' composites: 1950-2005 DJF
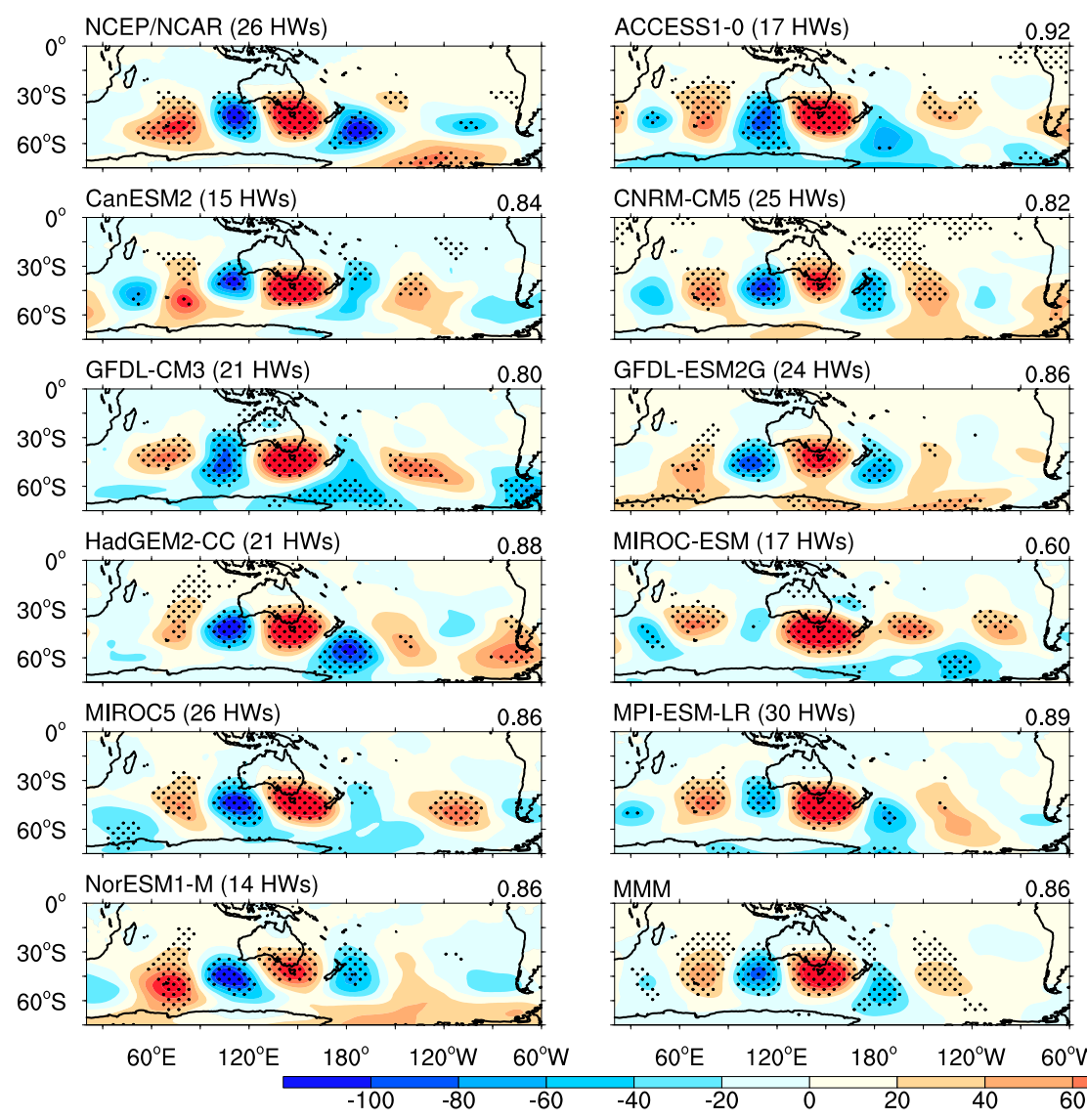

$60^{\circ} \mathrm{E} \quad 120^{\circ} \mathrm{E} \quad 180^{\circ} \quad 120^{\circ} \mathrm{W} \quad 60^{\circ} \mathrm{W}$
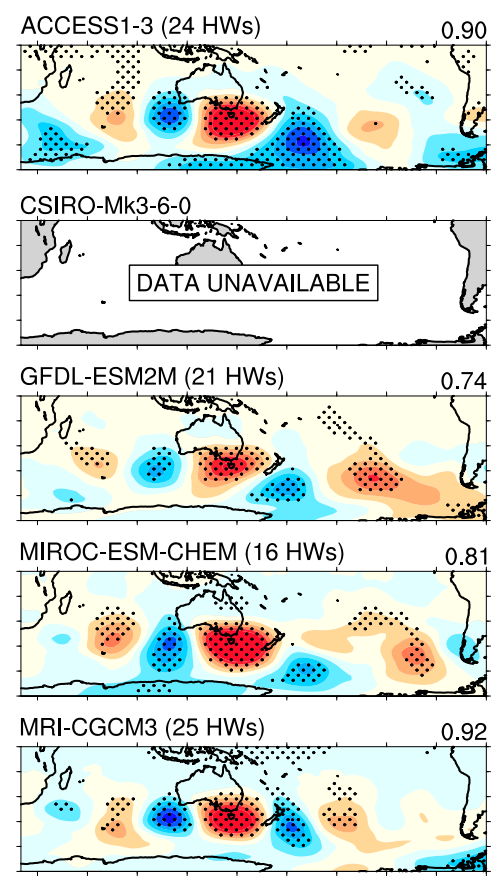

$60^{\circ} \mathrm{E} \quad 120^{\circ} \mathrm{E} \quad 180^{\circ} \quad 120^{\circ} \mathrm{W} \quad 60^{\circ}$

FIG. 6. As in Fig. 2, but for 500-hPa geopotential height anomalies (m). CSIRO Mk3.6.0 does not have data available.

with Fig. 6, where the anticyclone is centered over Tasmania). This indicates the baroclinicity of these blocking systems. Parker et al. (2013) suggest that tropical cyclones influence SEA heat wave development directly by reinforcing the upper-level ridge, and indirectly by exciting Rossby waves. Results here show little direct influence from the tropics. Rather they suggest that the Rossby wave trains emanating from the extratropical Indian Ocean dominate, in agreement with the findings of Boschat et al. (2014).

Figure 7 shows the positive $Z_{500}$ anomaly centered over SWA and the upstream negative $Z_{500}$ anomaly to be reasonably well simulated, although HadGEM2-CC, MIROC5, and NorESM1-M display overly broad subtropical ridge patterns. ${ }^{4}$ Pattern correlation coefficients range from 0.74 to 0.90 , with a median of 0.86 . As with SEA, the simulated $Z_{500}$ wave train centers over SWA display a westward displacement with respect to their MSLP counterparts, highlighting the baroclinic nature

\footnotetext{
${ }^{4}$ In NorESM1-M this contributes to tracking inconsistencies.
}

of these systems. There is a strong tendency for tropical lows to form near the northwest Australian coast, with many passing close to SWA during a heat wave event (Pezza et al. 2012). This is evident in the observed composite as a weak but statistically significant negative anomaly over the tropical Indian Ocean. Only three models (CNRM-CM5, HadGEM2-CC, and MIROC5) display statistically significant negative $Z_{500}$ anomalies in this region, although the majority of models capture the correct sign. This suggests that the tropical heat low to the northwest of Australia may play a role in directing tropical heat from the eastern tropical Indian Ocean across northern Australia to SWA.

\section{d. SST composites}

Local and remote SST anomalies are believed to play an important role in contributing to heat wave development (Pezza et al. 2012; Sadler et al. 2012; Boschat et al. 2014). Composites of daily SST anomalies for the week leading up to heat wave events for SEA and SWA are shown in Figs. 8 and 9, respectively. Because daily SST observations are only available from 1979 onward, 
SWA first HW day 500-hPa Z' composites: 1950-2005 DJF
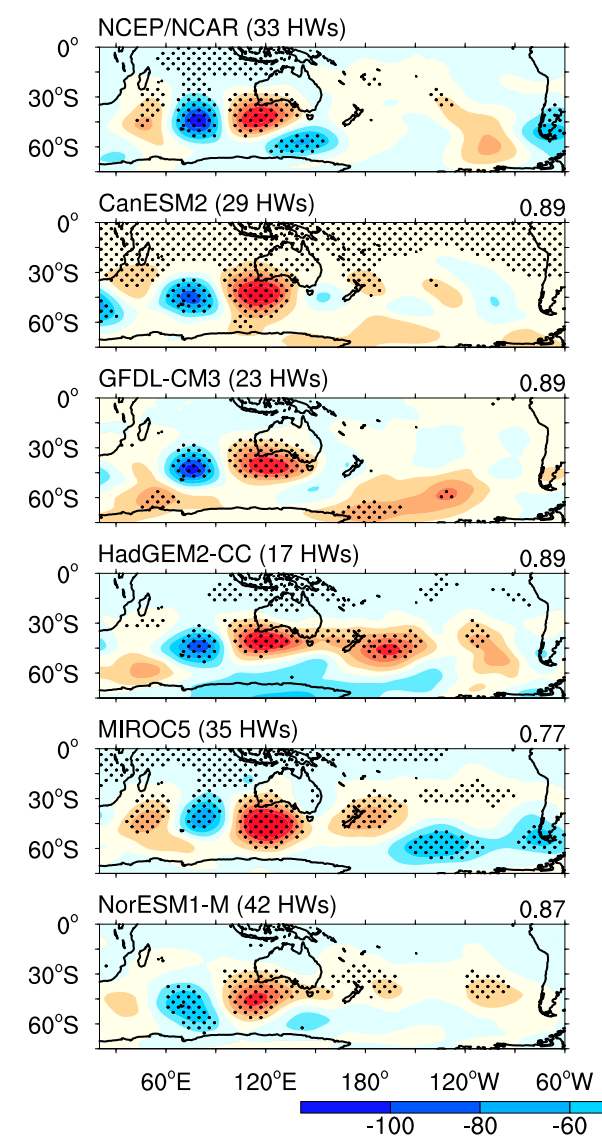
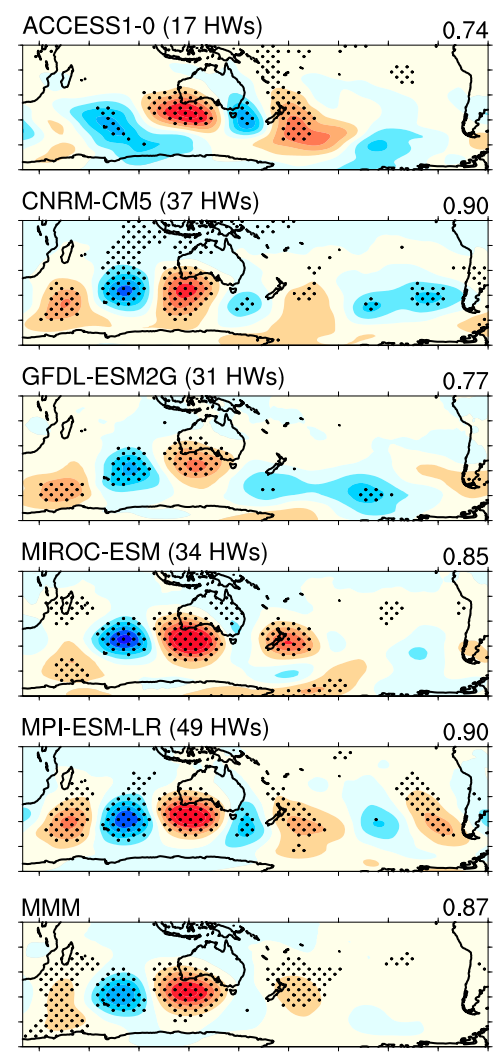

$60^{\circ} \mathrm{E} \quad 120^{\circ} \mathrm{E} \quad 180^{\circ} \quad 120^{\circ} \mathrm{W} \quad 60^{\circ} \mathrm{W}$
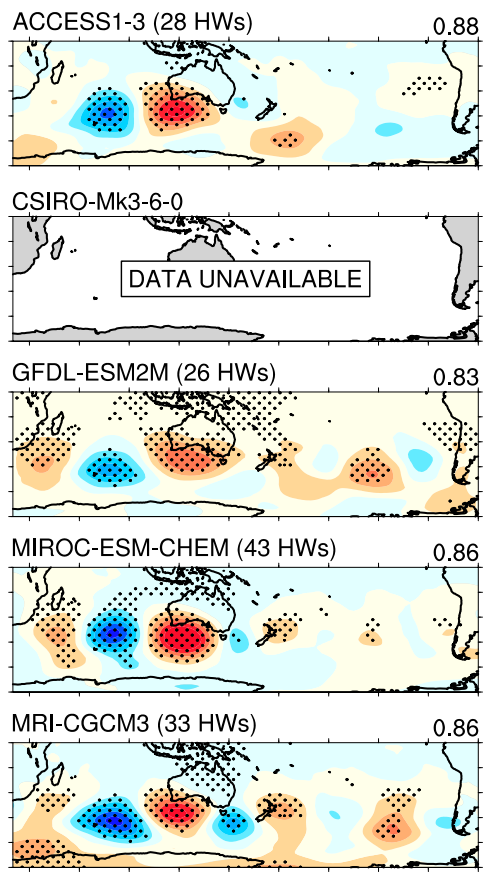

$60^{\circ} \mathrm{E} \quad 120^{\circ} \mathrm{E} \quad 180^{\circ} \quad 120^{\circ} \mathrm{W} \quad 60^{\circ}$

FIG. 7. As in Fig. 6, but for SWA. Pattern correlations are calculated over $10^{\circ}-60^{\circ} \mathrm{S}, 60^{\circ} \mathrm{E}-180^{\circ}$.

the observed composites comprise fewer heat wave events than atmospheric composites (12 events for SEA and 15 events for SWA).

For SEA heat waves, the observations show statistically significant cool SST anomalies in the Tasman Sea and east of New Zealand, consistent with previous studies (Sadler et al. 2012; Pezza et al. 2012). Significant warm SST anomalies in the Great Australian Bight are also seen (Boschat et al. 2014). Insignificant warm anomalies are seen across the Indian Ocean southeast of Africa, and across the Southern Ocean centered at $\sim 60^{\circ} \mathrm{S}$ (Fig. 8, top left; sparse regions of significance; Boschat et al. 2014).

The models have difficulty simulating the observed SST patterns associated with SEA heat waves (Fig. 8). Pattern correlation coefficients over the entire domain shown are very poor, ranging from -0.16 to 0.33 , with a median of 0.04 . This poor representation may not be specific to heat waves, but rather a more general deficiency in the ability of CMIP5 models to represent observed SST variability (e.g., Wang et al. 2014). None of the models is able to simulate SST patterns in all three of the regions identified as significant in the observations. Only CNRM-CM5 and GFDL-CM3 simulate cool Tasman Sea anomalies and many models actually simulate warm anomalies. HadGEM2-CC simulates a statistically significant cool anomaly east of New Zealand, and ACCESS 1.3 simulates a statistically significant cool anomaly farther southeast; however, again, the majority of models do not simulate a cooling in this region. Many models do simulate warm anomalies in the Great Australian Bight: GFDL-ESM2G, GFDL-ESM2M, and MIROC-ESM show significance in this region. In fact, the MMM shows a broad band of midlatitude warming, incorporating the Great Australian Bight, but also the Tasman Sea. Further, most models simulate warm anomalies southeast of Africa, although the exact location of this warm anomaly varies among the models, and few are statistically significant (including the observed warming). The most prominent region of SST anomalies simulated by the models that is consistent with the observations is the band of warm anomalies across the Southern Ocean. This warming is significant in CanESM2, CNRM-CM5, GFDL-ESM2G, MPI-ESM-LR, 
SEA week prior to HW SST' composites: 1950-2005 DJF
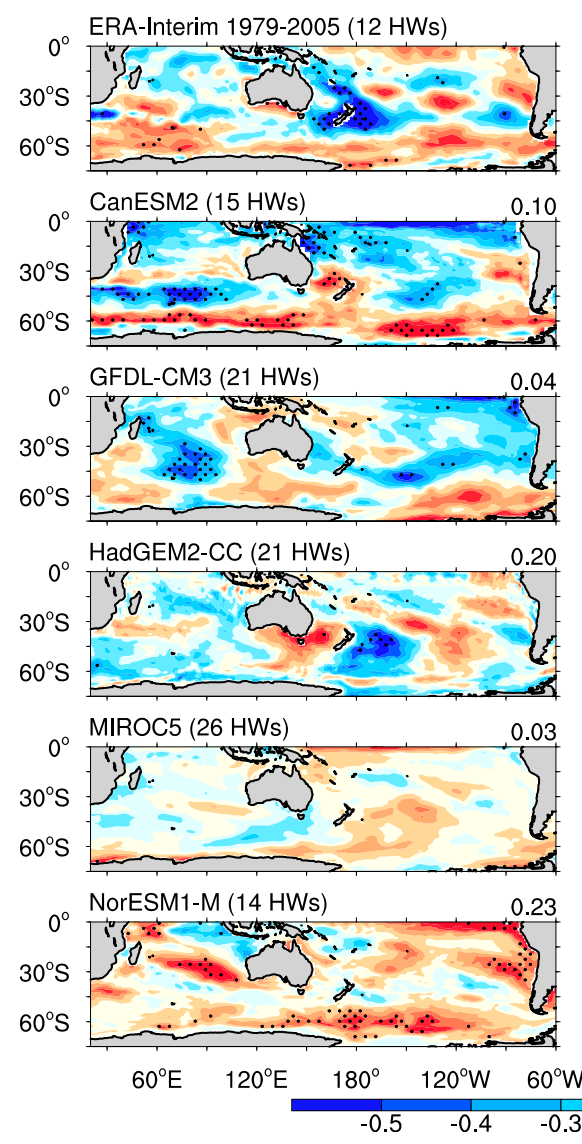
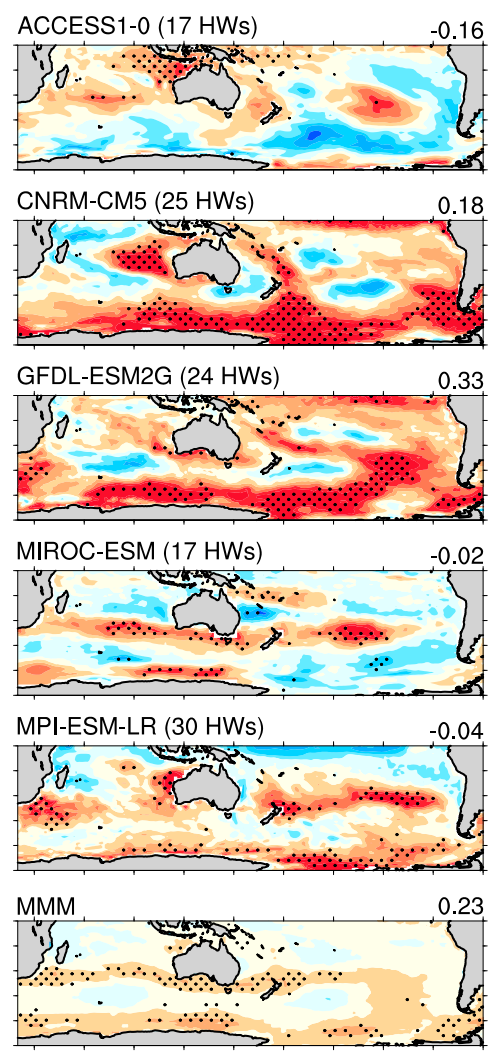

$60^{\circ} \mathrm{E} 120^{\circ} \mathrm{E} \quad 180^{\circ}-120^{\circ} \mathrm{W}-60^{\circ} \mathrm{W}$
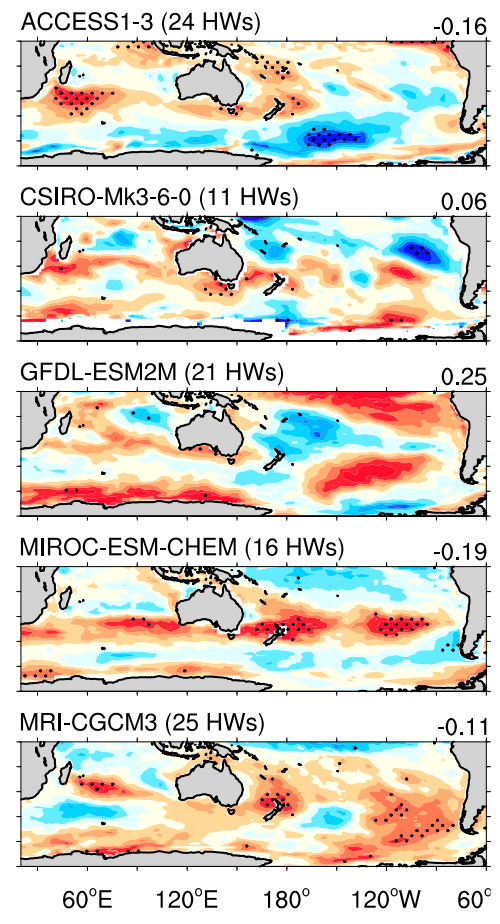

FIG. 8. As in Fig. 2, but for SST anomalies $\left({ }^{\circ} \mathrm{C}\right)$ for the week prior to the first day of heat waves in SEA. Pattern correlations are calculated over $0^{\circ}-75^{\circ} \mathrm{S}, 20^{\circ} \mathrm{E}-60^{\circ} \mathrm{W}$.

and NorESM1-M and in limited regions in MIROCESM and MRI-CGCM3; thus it is prominent in the MMM. This assessment raises the question as to the importance of SST patterns leading up to heat waves in SEA. It is possible that in the CMIP5 models a warm Southern Ocean is more influential in the onset of SEA heat waves compared to the Indian Ocean and Tasman Sea, as has been previously reported for observations (Pezza et al. 2012).

The models appear to better simulate the SST anomaly patterns for the week leading up to SWA heat waves (Fig. 9). Some models still display very poor pattern correlations (minimum correlation coefficient of -0.14 ) but many others show moderate correlations (maximum correlation coefficient of 0.48 and median of 0.29). In the observations a subtropical dipole is seen in the Indian Ocean, with a cool anomaly (a portion of which is statistically significant) seen southeast of southern Africa, and a statistically significant warm anomaly to the north (east of Madagascar; Fig. 9, top left). The Indian Ocean temperature anomalies appear to be similar to the negative phase of the Indian Ocean subtropical dipole (e.g., Behera and Yamagata 2001; Suzuki et al. 2004). The negative phase of the subtropical dipole is associated with anomalously low MSLP over the subtropical Indian Ocean, resulting in anomalous southeasterly winds that cause increased evaporation and upper ocean mixing, and thus cooling over the cold western pole (Behera and Yamagata 2001; Suzuki et al. 2004). Most models capture the anomalous SST subtropical dipole in the Indian Ocean, although the spatial extent and position of the poles varies from model to model. Many models simulate the warm eastern pole closer to the northwest Australian coast (as seen in the MMM). Almost all models show the warm anomaly to be statistically significant, but as with the observations, the cool anomalies are often only significant over a limited area.

It is uncertain whether this negative subtropical dipole pattern displayed is a result of the atmosphere influencing the ocean or vice versa. However, it seems likely that the atmosphere influences the ocean through 
SWA week prior to HW SST' composites: 1950-2005 DJF

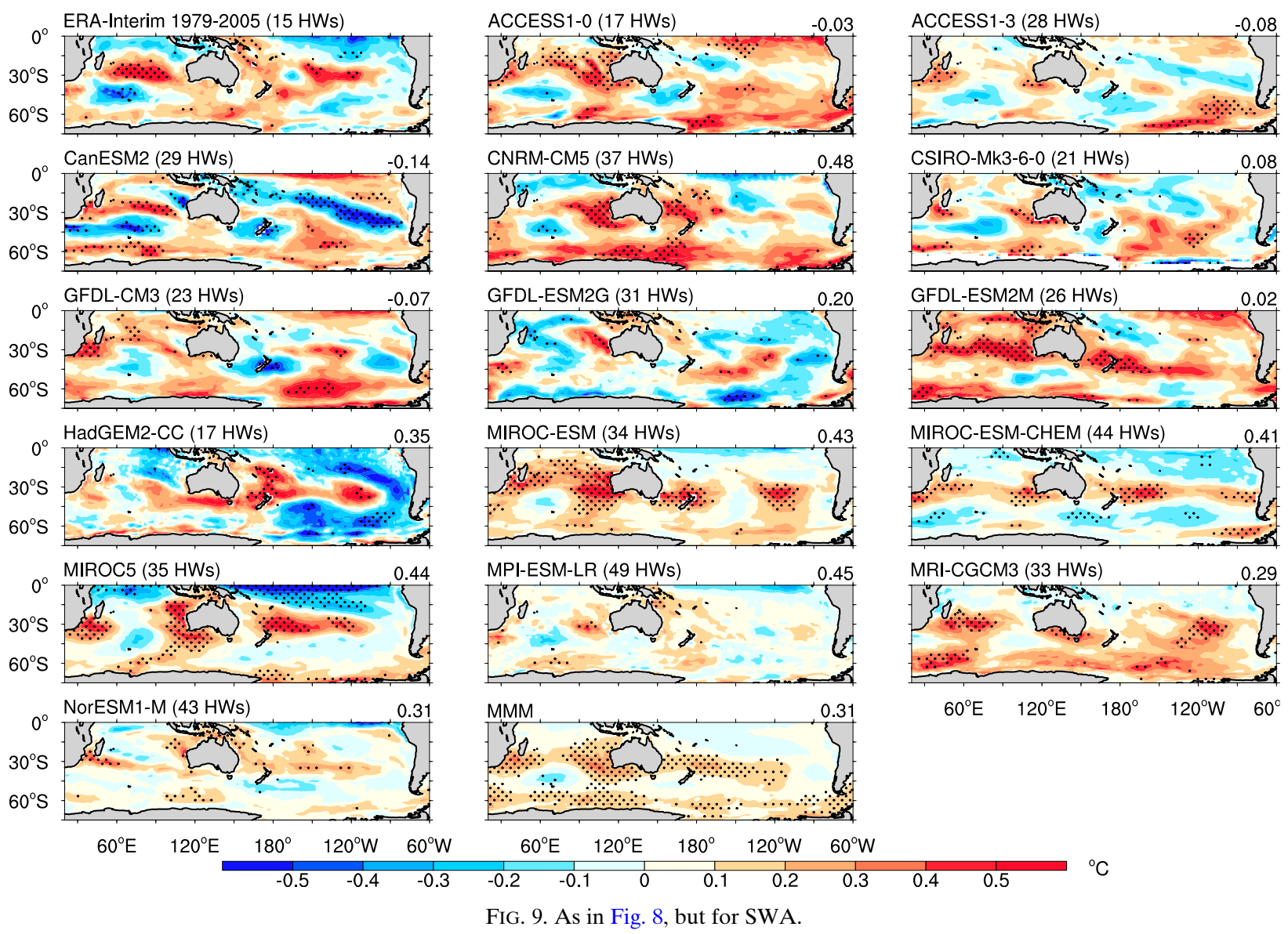

a southward shift and strengthening of the subtropical high (Morioka et al. 2012). The SST anomalies associated with the dipole are believed to be induced by the anomalous north-south shifts of the anticyclone southeast of Madagascar (the Mascarene high; Fauchereau et al. 2003), with remote teleconnections to Tasman Sea SSTs (Fig. 9). This remote teleconnection is not seen in the observed SST composite for SWA; however, a number of models simulate a subtropical dipole-Tasman Sea association. Warm anomalies are also observed off the northeast coast of Australia and in the Southern Ocean across the Indian sector. Many of the models capture these features, but with varying significance.

\section{Future heat wave climatologies}

It is of interest to determine whether atmospheric conditions associated with southern Australian heat waves will change under a warming climate. That is, could circulation changes associated with increasing atmospheric greenhouse gas concentrations lead to synoptic conditions more (less) favorable to heat waves in southern Australia, and cause heat wave metrics to increase faster (slower) than expected from changes in the mean-state local temperature alone? Investigating future changes in heat wave events for SEA and SWA, however, proves quite complicated, as a mean-state warming is intricately linked with local dynamical changes, such as rising surface pressure (Timbal et al. 2010). Further, any rise in the local mean-state temperature that leads to an increase in heat wave events at a particular location may be masking dynamical changes that also contribute to more heat extremes.

\section{a. MSLP pattern regression}

For the future period, creating a composite of atmospheric and oceanic conditions associated with "all" heat wave events to compare with the historical period is not necessarily representative of the dynamical changes associated with these events. With an increase in the mean-state temperature, events that in the historical period may have been slightly below the heat wave temperature threshold should surpass it in the future period, regardless of dynamics. Therefore, a simple 
comparison of historical and future heat wave composites is not useful. Instead, we use pattern regression analysis to determine whether the classical synoptic setup for southern Australian heat waves is projected to change in the future.

For each model, the MSLP anomaly associated with each individual heat wave event that occurs in both the historical and future periods is regressed onto the MSLP anomaly composite pattern of the historical period (Figs. 4 and 5). Rather than using the broader domains used in calculating pattern correlation coefficients, here we are interested in the immediate conditions affecting heat wave events. As such, regression coefficients are calculated over a smaller region that encompasses the historical MSLP couplet: $15^{\circ}-60^{\circ} \mathrm{S}, 100^{\circ} \mathrm{E}-180^{\circ}$ for SEA and $20^{\circ}-55^{\circ} \mathrm{S}, 70^{\circ}-150^{\circ} \mathrm{E}$ for SWA. For the historical period, the average regression coefficient is by definition 1 , and the regression coefficients for individual heat waves tend to be close to 1 . In the future, whether regression coefficients increase notably above or below 1 indicates whether there is a change in the intensity (strengthening or weakening) or location (such as a poleward shift) of the classic synoptic setup associated with heat waves, with respect to the historical period.

Figures 10 and 11 show the regression coefficients over the region of the composite anticyclone and the upstream cyclone associated with heat wave events, for SEA and SWA, respectively. Heat wave events with pattern regression coefficients above one are shown in red, and below one are shown in blue. In the future period an overall increase in the number of points is to be expected, because of a mean-state warming. More red points relative to the historical period indicates that the MSLP couplet pattern is above the historical average (intensifying), while more blue points indicates a weakening or change in the synoptic setup.

For SEA (Fig. 10), a larger increase in the number of blue points compared to red points into the twenty-first century demonstrates that more heat wave events are occurring without the canonical heat wave pressure couplet setup of the historical period. The maximum regression of heat waves (red points) seems to be capped over 1950-2100, while the minimum regression of heat waves (blue points) continues to decrease over time in most models. This suggests that in SEA, by 2100 under the RCP8.5 scenario, even without the historical "heat wave setup" characteristics, heat waves are able to occur. Thus, the majority of the increase in the number of heat wave events appears to be caused by the mean-state temperature increase alone. Some models such as CNRM-CM5 simulate an intensification of the classical historical pressure couplet for some heat waves in the mid-twenty-first century (as shown by the outlying red points), whereas others including CSIRO Mk3.6.0 and MRI-CGCM3 suggest that this setup has substantially diminished by 2100 .

The increase in the number of heat wave events for SWA is much larger than for SEA ( $\sim 20$-fold increase for SWA compared to $\sim 6$-fold increase for SEA by 2100; Cowan et al. 2014). For SEA, the majority of models show more future heat waves with a weakened or shifted pressure setup (blue points) over time. For SWA, this is even more apparent because of the greater overall increase in the number of heat waves. Some models such as the MIROC models indicate that by 2100 the mean atmospheric setup required to generate a heat wave will be very different from the historical period (large increase in blue points). Others such as GFDLESM2G and NorESM1-M show the large increase in the blue points to be accompanied by an increase in red points, indicative of large variations in the pressure setup for future heat waves. This suggests that for SWA, while the number of heat waves that occur without the classical heat wave setup is increasing in the future (i.e., due to the mean-state temperature increase), in some models there is also an increase in the classical heat wave setup (intensification).

If a weakening and/or shift of the pressure couplet pattern were to occur in the case of no mean-state warming, one might assume a decrease or very little change in future heat wave events. This suggests that future warming leads to more heat wave events overall, but that more of these events occur under a weakened classical pressure setup, because

1) weaker anticyclones are able to generate heat waves in the future (which would have only been warm events historically) due to increased mean temperatures;

2) anticyclones are shifting poleward, but are more intense (e.g., Kent et al. 2013), changing the atmospheric setup (more blue points) but also leading to more heat waves; or

3) a combination of these two processes (i.e., weaker anticyclones generating heat waves as well as more intense anticyclones shifting south, but generating heat waves more frequently) is at work.

To elucidate what changes are projected to occur, composites of select heat wave events are next presented.

\section{b. MSLP maximum and minimum decile composites}

Over the period 1950-2100, composites of the MSLP anomalies for heat waves with regression coefficients in the maximum and minimum deciles are constructed. These composites comprise the events above (maximum decile) and below (minimum decile) the dashed lines 


\section{SEA HW MSLP' composite regression: 1950-2100 DJF}
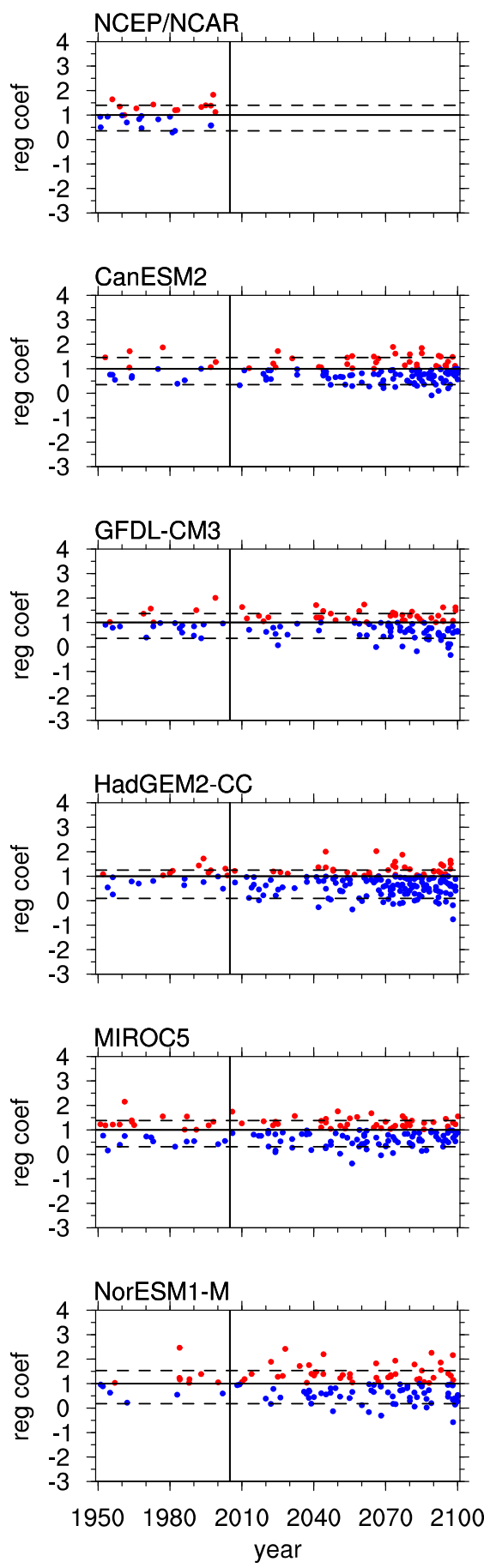
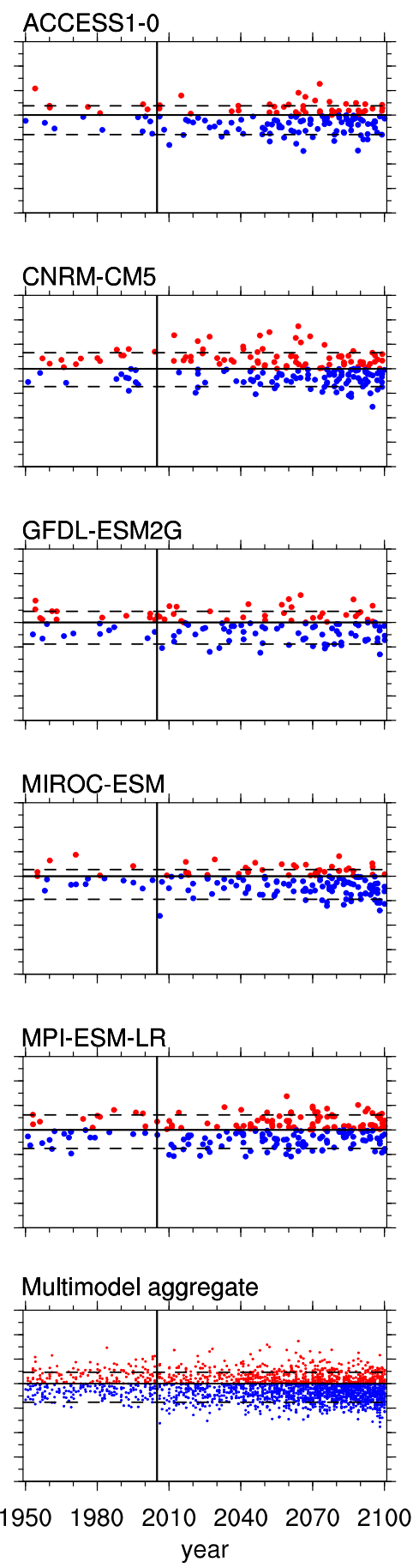
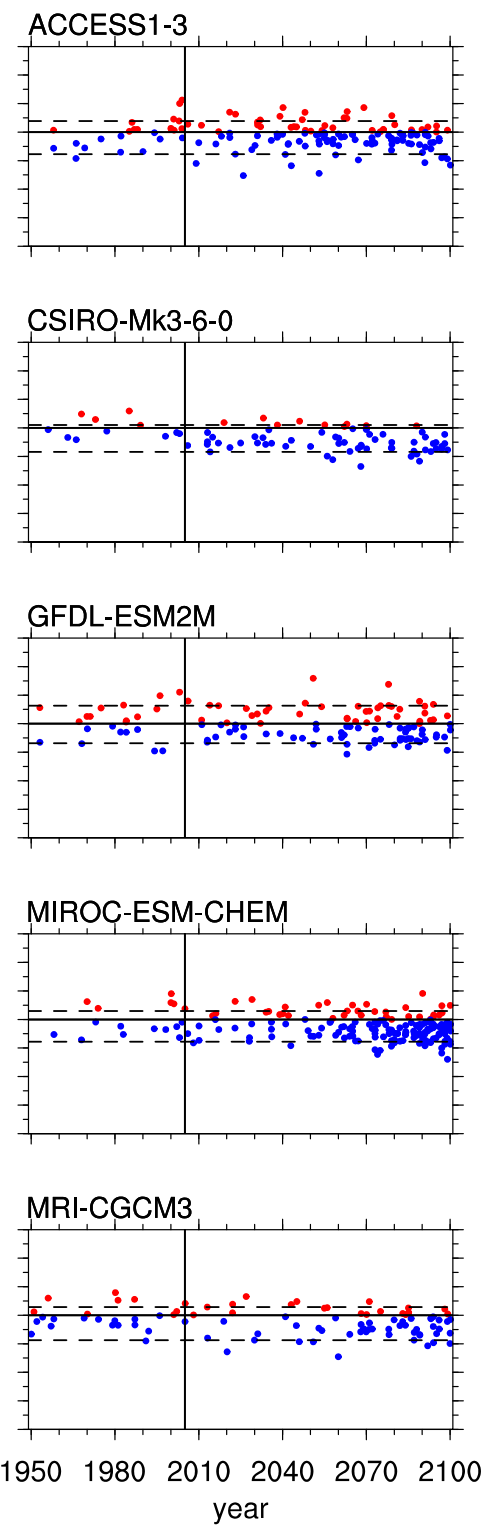

FIG. 10. Pattern regression coefficients of individual SEA heat wave events onto the 1950-2005 composite MSLP pattern versus time for observations over 1950-2005 and for models over 1950-2100. A multimodel aggregate is also shown (bottom center panel). Regression coefficients are calculated over the approximate anticyclone and cyclone locations: $15^{\circ}-60^{\circ} \mathrm{S}, 100^{\circ} \mathrm{E}-180^{\circ}$. Regression coefficients $>1$ are shown in red and $<1$ in blue. The reference lines are the year 2005 and the regression coefficient 1 . The maximum- and minimum-decile regression coefficients for each model are shown by the upper and lower dashed lines in each panel, respectively. For the multimodel aggregate panel, smaller marker sizes are used. 
SWA HW MSLP' composite regression: 1950-2100 DJF
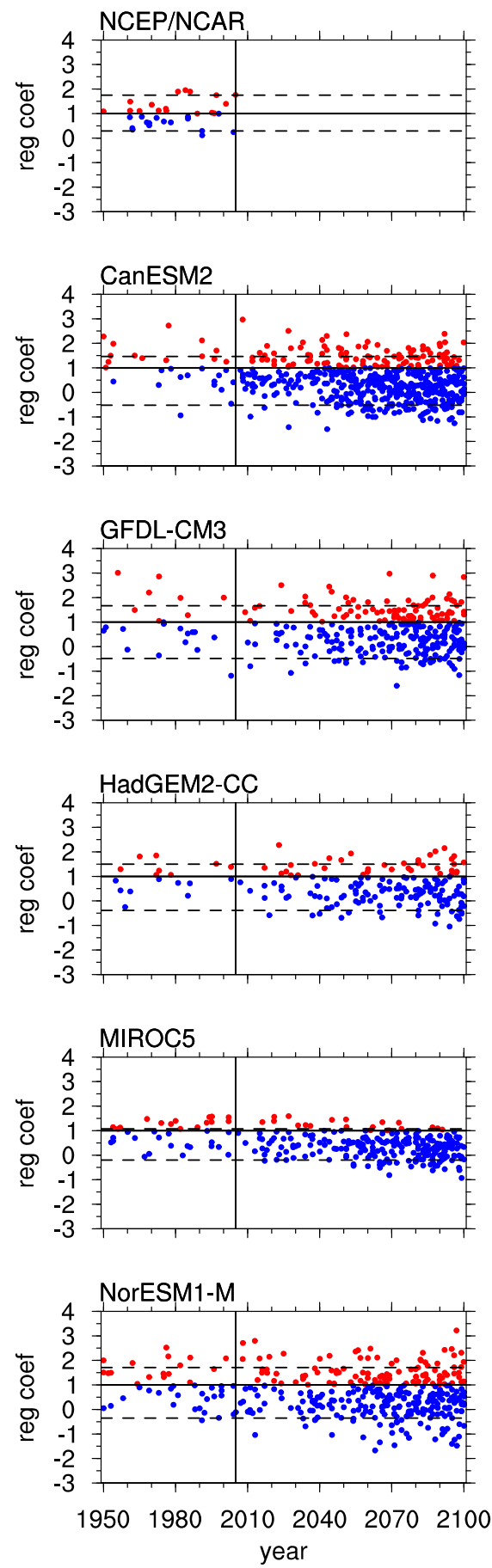

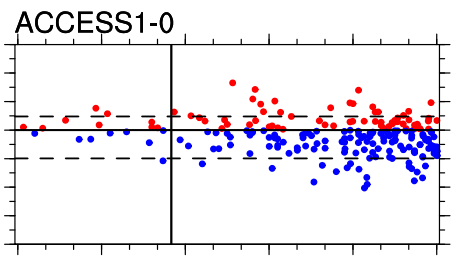

CNRM-CM5

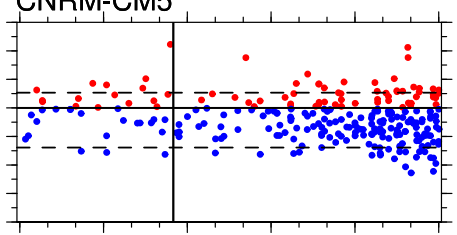

GFDL-ESM2G

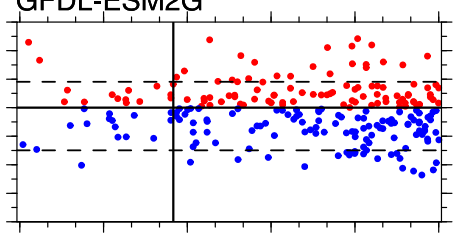

MIROC-ESM

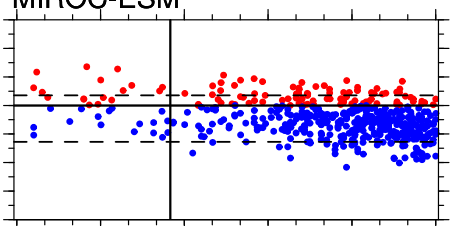

MPI-ESM-LR
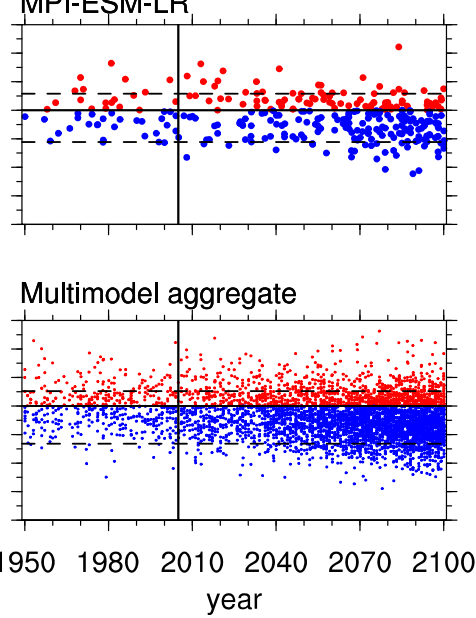

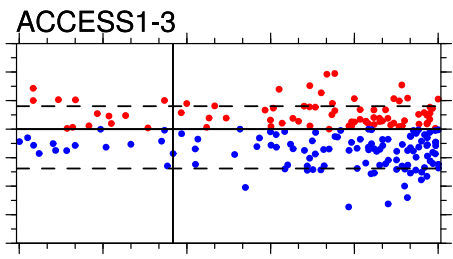

CSIRO-Mk3-6-0

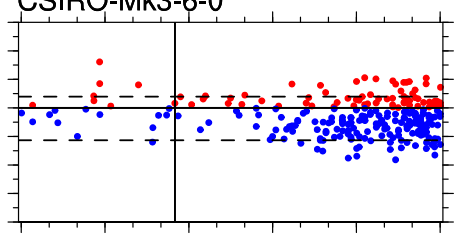

GFDL-ESM2M

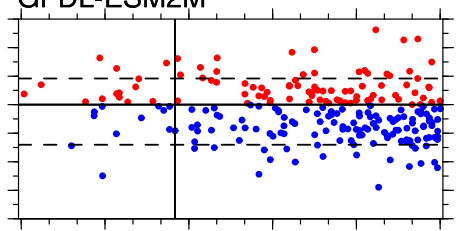

MIROC-ESM-CHEM

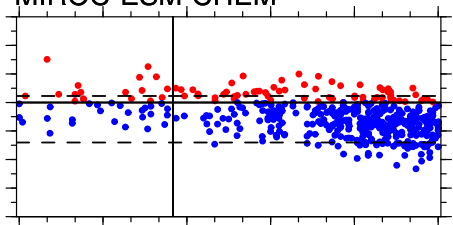

MRI-CGCM3

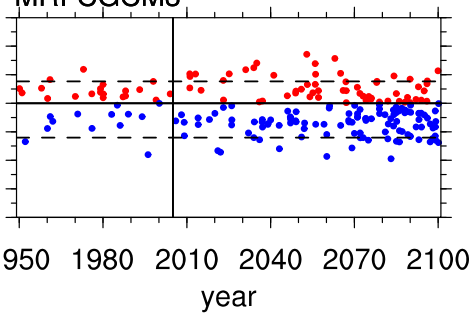

FIG. 11. As in Fig. 10, but for SWA. Regression coefficients are calculated over the approximate anticyclone and cyclone locations: $20^{\circ}-55^{\circ} \mathrm{S}, 70^{\circ}-150^{\circ} \mathrm{E}$.

shown in Figs. 10 and 11. The decile thresholds are calculated for observations and for each model separately, over the full period (1950-2005 for observations and 1950-2100 for models).
As expected, the SEA maximum-decile composites (Fig. 12) show the MSLP couplet centers to be located in similar positions, but shifted slightly poleward, compared to their historical-composite counterparts. One or 
SEA first HW day MSLP' maximum-decile regression composites: 1950-2100 DJF

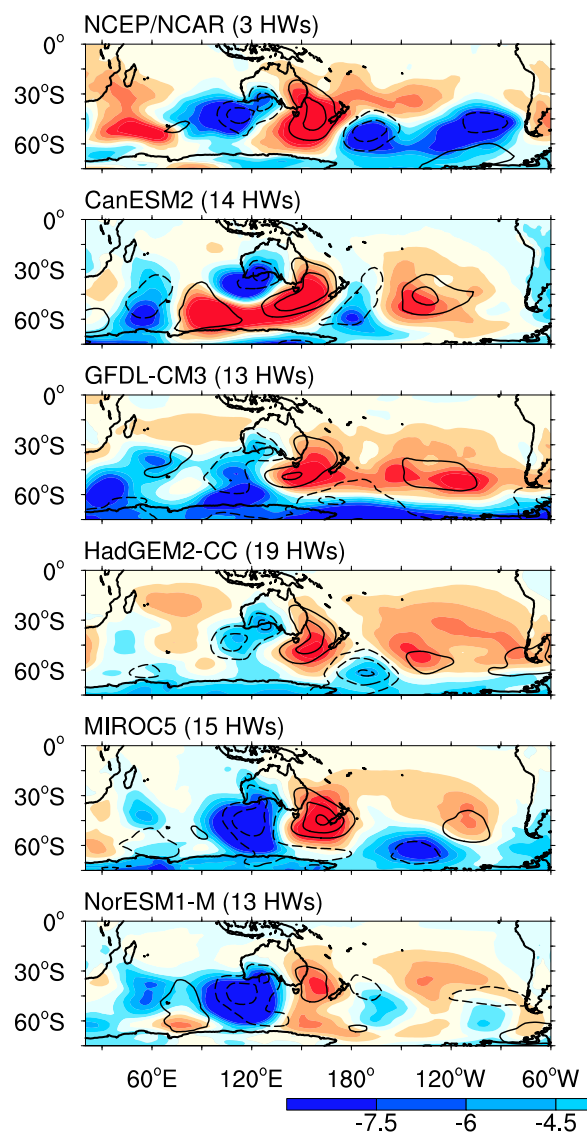

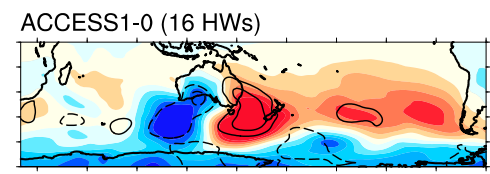

CNRM-CM5 (19 HWs)

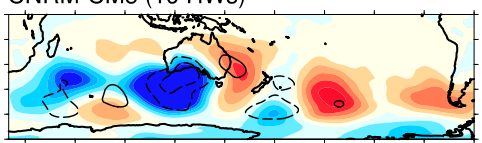

GFDL-ESM2G (13 HWs)

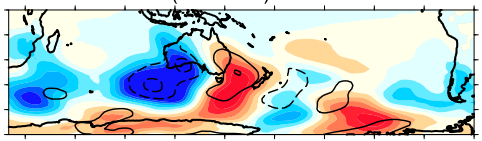

MIROC-ESM (16 HWs)
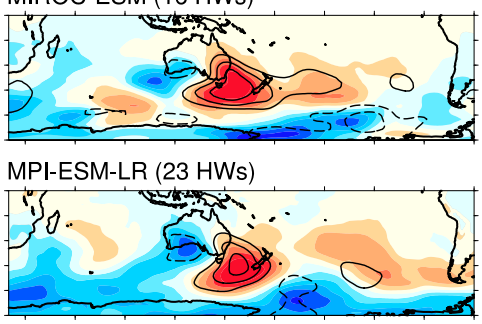

MMM

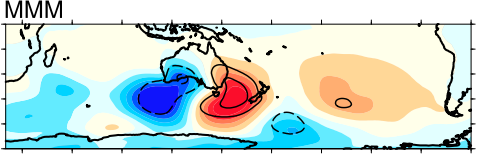

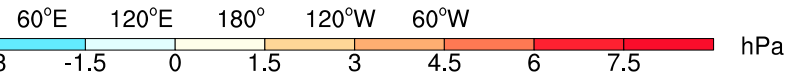

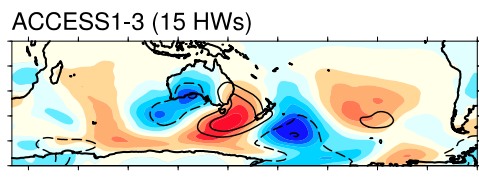

CSIRO-Mk3-6-0 (8 HWs)

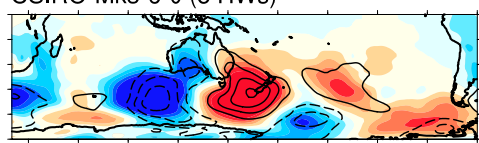

GFDL-ESM2M (12 HWs)

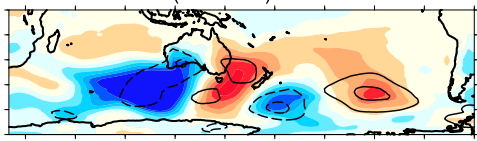

MIROC-ESM-CHEM (18 HWs)

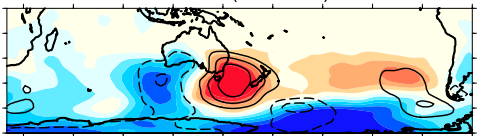

MRI-CGCM3 (10 HWs)

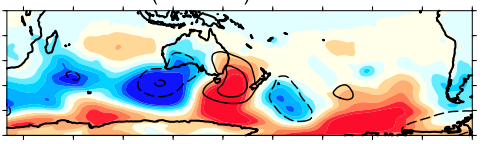

$60^{\circ} \mathrm{E} \quad 120^{\circ} \mathrm{E} \quad 180^{\circ} \quad 120^{\circ} \mathrm{W} \quad 60^{\circ}$

FIG. 12. As in Fig. 2, but for MSLP anomalies (hPa) for the first day of maximum decile heat waves over SEA over 1950-2100. The highest decile events are based on the pattern regression coefficient values from Fig. 10. Anomalies are referenced to the 1950-2005 climatology. Contours (interval $3 \mathrm{hPa}$ ) indicate historical MSLP composite centers (Fig. 4): solid (dashed) contours indicate positive (negative) anomalies, and the zero contour is not shown.

(in most cases) both of the pressure centers are stronger than in the historical composite. With the increased occurrence of heat waves in the future, despite the more obvious increase in the number of low-regression coefficient events (blue points), there is still an increase in the number of high-regression coefficient events (red points; Fig. 10). The maximum-decile composites are therefore composed of more events from late in the twenty-first century (2045-2100) than in the historical period (1950-2005). This suggests that the historical classical MSLP setup causing SEA heat waves still persists in the future climate.

The SEA minimum-decile composites (Fig. 13) still show an anticyclone center over the Tasman Sea, but this system is weaker than the historical composite (cf. shading and contours). A low pressure system is centered over SWA but is more localized than in the historical composite. To the south of this, there is a strong high pressure ridge, which is likely contributing to the low/negative regression coefficients, as in the historical composite this is a region of anomalously low MSLP. Over the Southern Ocean, the minimum-decile composite displays a SAM-like pattern; however, because there is still a MSLP couplet over SEA, even though the pressure centers are weak, northerly winds are still induced toward SEA. The vast majority of minimumdecile regression coefficient heat waves occur in the future (2045-2100) under increased mean-state temperature conditions. In this new climate regime of higher maximum temperatures, the weakened MSLP setup is still sufficient to cause a heat wave across SEA.

As for SEA, the SWA maximum-decile composites (Fig. 14) show the MSLP couplets to be located similarly, but with a slight poleward shift, to their historicalcomposite counterparts (cf. shading and contours), as well as being stronger. The SWA minimum-decile composites (Fig. 15) show a low pressure system south of Australia, as opposed to the historical-composite high 
SEA first HW day MSLP' minimum-decile regression composites: 1950-2100 DJF
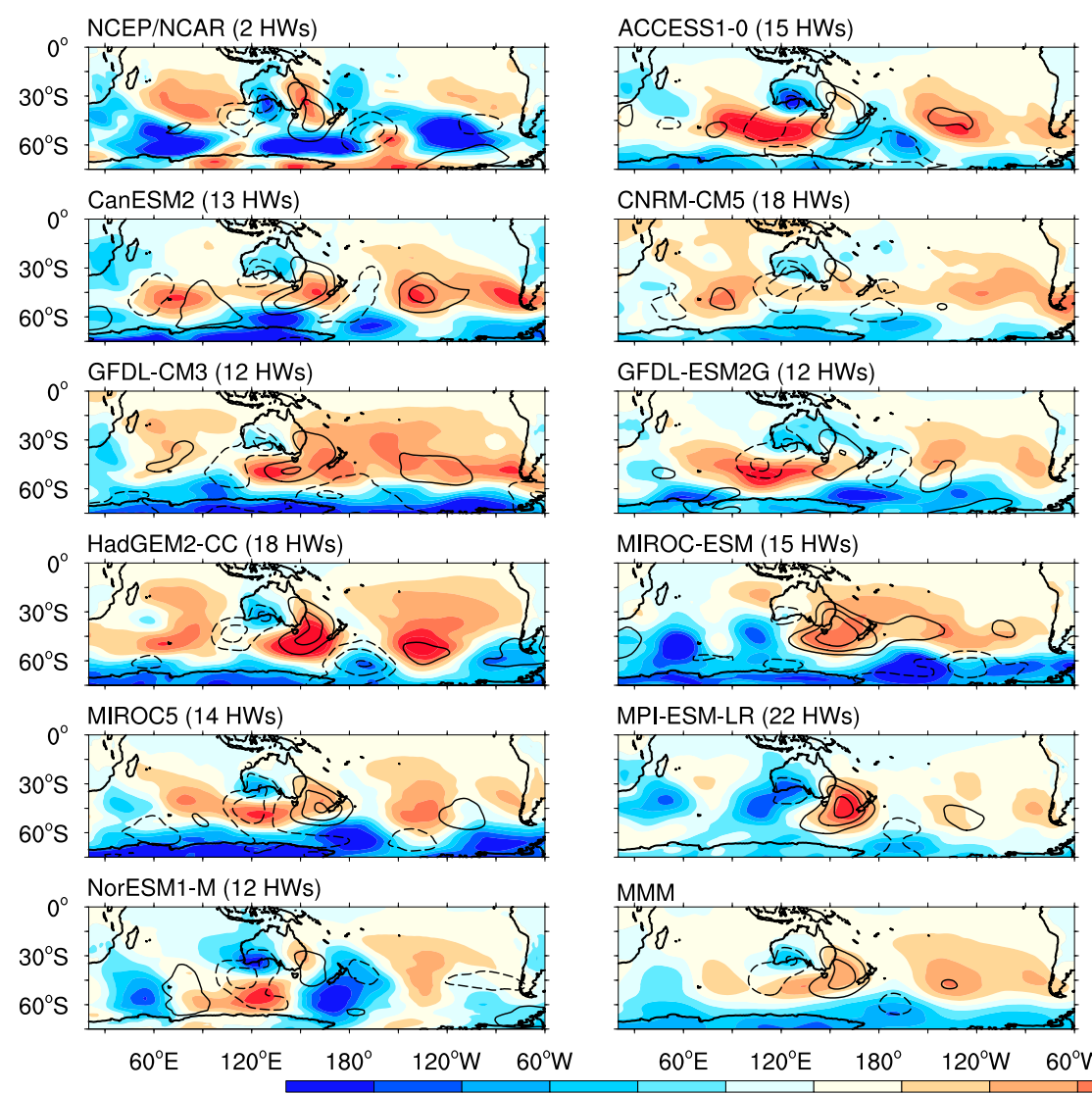

$60^{\circ} \mathrm{E} \quad 120^{\circ} \mathrm{E} \quad 180^{\circ} \quad 120^{\circ} \mathrm{W} \quad 60^{\circ} \mathrm{W}$

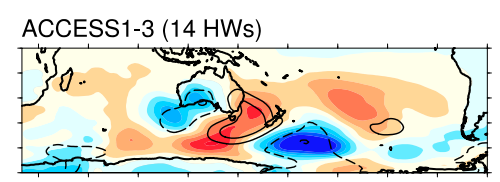

CSIRO-Mk3-6-0 (7 HWs)
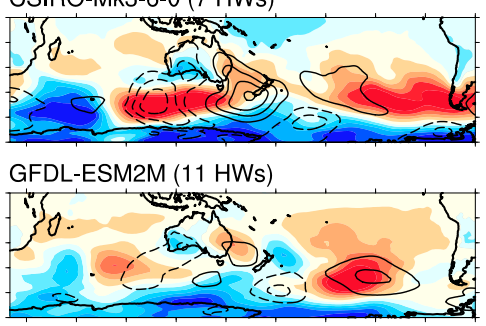

MIROC-ESM-CHEM (17 HWs)

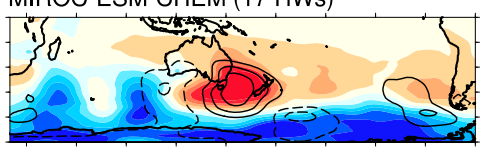

MRI-CGCM3 (9 HWs)

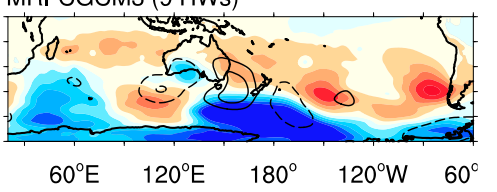

FIG. 13. As in Fig. 12, but for minimum decile events.

pressure center, leading to low/negative regression coefficients. Compared to the canonical heat wave inducing high centered over the Great Australian Bight, the minimum-decile composite low pressure center is located farther south. This allows the high pressure system, located to the southwest of SWA (in a similar position to the historical-composite low pressure system) to form a weak pressure ridge toward the northeast. Because of the presence of the ridge, there is a weak positive MSLP anomaly over the tip of SWA. This is sufficient to direct weak winds from the interior of the continent toward the southwest. As with SEA, with an increased mean-state temperature in the future, such winds will cause heat waves across SWA; whereas in the historical period, this type of setup is not associated with heat wave development.

These findings suggest that the majority of the increase in the number of heat wave events for southern Australia is caused by the mean-state temperature increase. Furthermore, Cowan et al. (2014) find heat wave amplitude (measured as the maximum temperature of the hottest summer event) to be increasing at a faster rate than the mean. This is thought to be caused by mean temperatures in central Australia warming at a faster rate than coastal regions (Cowan et al. 2014). This is consistent with results found here: a warmer interior would also allow weaker synoptic setups to generate heat wave conditions.

To test whether the blocking anticyclones associated with the onset of the hottest heat wave events are projected to increase in intensity and shift poleward in the future [as shown for the mean conditions by Kent et al. (2013)] these synoptic systems are tracked for both the historical (1950-2005) and latter future (2045-2100) periods.

\section{c. Anticyclone tracks}

Using the Melbourne University tracking scheme, the anticyclones associated with SEA and SWA heat waves are determined for the first day of each heat wave event and tracked back in 6-hourly intervals for a total of 10 days. Because the number of heat wave events in the 
SWA first HW day MSLP' maximum-decile regression composites: 1950-2100 DJF

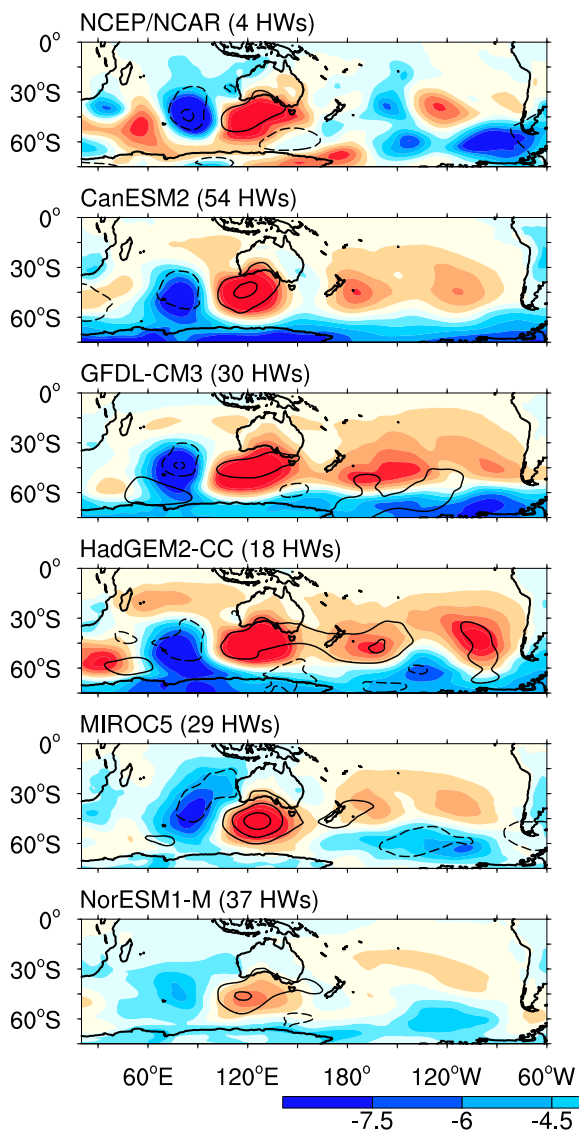

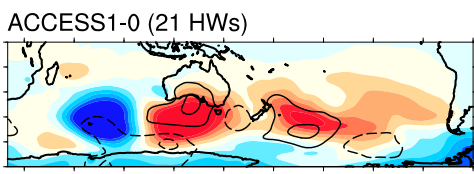

CNRM-CM5 (26 HWs)

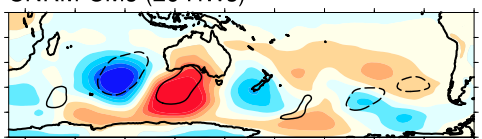

GFDL-ESM2G (24 HWs)

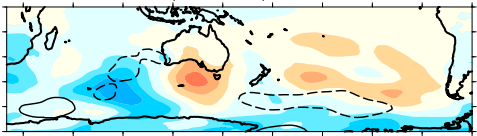

MIROC-ESM (47 HWs)

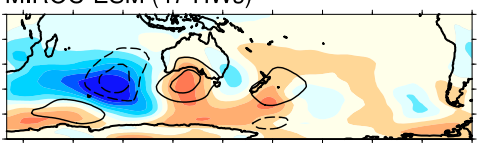

MPI-ESM-LR (32 HWs)

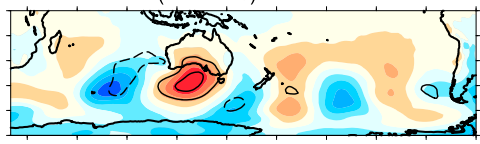

MMM

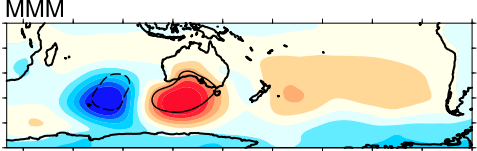

$60^{\circ} \mathrm{E} 120^{\circ} \mathrm{E} \quad 180^{\circ}-120^{\circ} \mathrm{W}$ - $60^{\circ} \mathrm{W}$

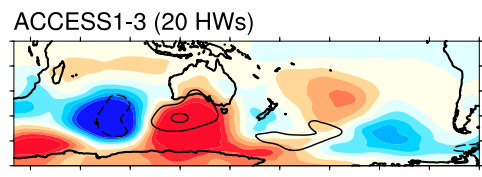

CSIRO-Mk3-6-0 (25 HWs)

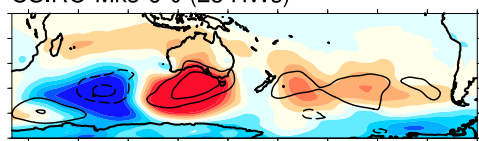

GFDL-ESM2M (23 HWs)

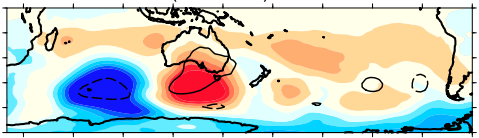

MIROC-ESM-CHEM (45 HWs)

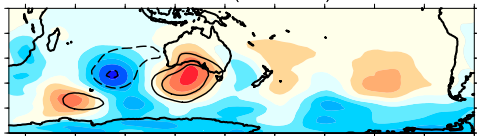

MRI-CGCM3 $(21 \mathrm{HWs})$

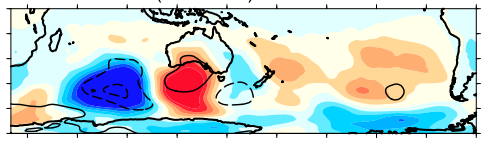

$60^{\circ} \mathrm{E} \quad 120^{\circ} \mathrm{E} \quad 180^{\circ} \quad 120^{\circ} \mathrm{W} \quad 60^{\circ}$

FIG. 14. As in Fig. 12, but for SWA based on maximum decile events from the pattern regression coefficient values from Fig. 11. Contour lines indicate historical MSLP composite centers (Fig. 5).

twenty-first century is much increased compared to the historical period, heat wave events for tracking purposes are instead defined using nonstationary threshold temperatures. That is, a heat wave event is defined relative to that period's specific climatology. This allows a comparable number of heat waves to be tracked in each period, so that the comparison between periods is reasonable.

As in Cowan et al. (2014), we use a centered 31-yr sliding window (sufficient to filter out interannual variability) to calculate the threshold temperatures, rather than the fixed 1950-2005 climatology. For example, the threshold temperatures for 1980 are based on 1965-95 climatology. The threshold temperatures for the first and last 16 years are based on fixed windows (1950-80 and 2070-2100, respectively). This nonstationary climatology effectively detects only the hottest heat waves and removes increases in the simulated number of events. Using this nonstationary definition, for SEA, the multimodel aggregate number of heat waves is 317 over 1950-2005 and 312 over 2045-2100. For SWA, the multimodel aggregate number of heat waves is 443 over 1950-2005 and 429 over 2045-2100.

Multimodel ensembles of the anticyclone tracks and their central pressures associated with heat waves are shown in Fig. 16. Not every track is 10 days long, so the uncertainty grows larger at each time interval. Ten days prior to historical SEA heat waves, the composite anticyclone is located in the southern-central Indian Ocean $\left(\sim 36^{\circ} \mathrm{S}, 70^{\circ} \mathrm{E}\right)$. This anticyclone intensifies for $\sim 2$ days, as it tracks toward the SWA coastline, before weakening as it passes south of southern Australia (not shown). As the composite anticyclone passes through Bass Straight and into the Tasman Sea it rapidly reintensifies, as the blocking cycle that generates a SEA heat wave commences. In the RCP8.5 simulation, the tracks are located farther poleward by $\sim 2^{\circ}$, and 10 days prior to heat wave events the composite anticyclone is located farther west $\left(\sim 62^{\circ} \mathrm{E}\right)$, implying that these systems move at a greater velocity compared to those in the historical period. The RCP8.5 anticyclone tracks and their central pressures follow the same evolution as in the historical period 
SWA first HW day MSLP' minimum-decile regression composites: 1950-2100 DJF
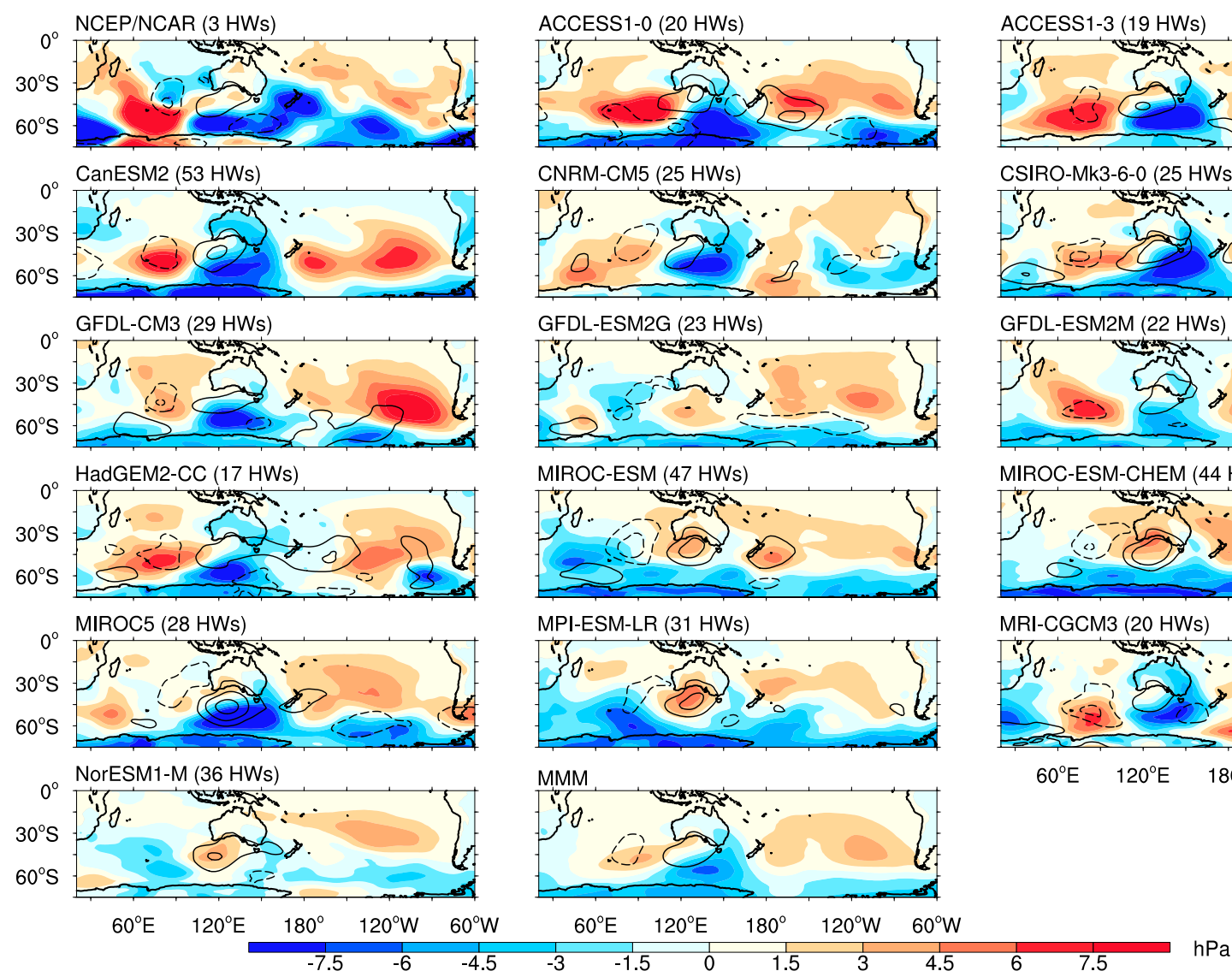

FIG. 15. As in Fig. 14, but for minimum decile events.

(Fig. 16, left panels, red); however, their central pressures are significantly stronger, and the tracks maintain their poleward displacement until the commencement of heat wave events.

For SWA heat waves, the anticyclone tracks are situated farther west over the subtropical Indian Ocean $\left(\sim 45^{\circ} \mathrm{E}\right)$. The eastward movement of the anticyclone coincides with a gradual increase in its central pressure, from $\sim 1022.5 \mathrm{hPa} 10$ days prior to the heat wave to $1024 \mathrm{hPa}$ on the first day of the heat wave (Fig. 16, right panels, green). As for SEA, the RCP8.5 track exhibits a similar evolution (a poleward shift and originating farther west compared to the historical track). There is an overlap in the uncertainty estimates between the positions of historical and RCP8.5 simulations, despite the central pressures in the future simulation showing a greater strengthening across the entire track length than seen for SEA.

These results emphasize the impact that future warming will have on the blocking anticyclones that evolve to become heat wave-inducing events. In a warmer climate, the models suggest that these blocking systems will be located farther poleward and their central pressures will be stronger. Despite blocking anticyclones being located farther from the regions of interest (SEA and SWA) by the late twenty-first century, their area of influence appears to be more than offset by the increased strength of their central pressures. These changes in surface pressure are consistent with previous studies into future changes in the intensity and displacement of the Australian subtropical ridge (Kent et al. 2013; Timbal et al. 2010) and poleward shifts in Southern Hemisphere storm tracks (e.g., Chang et al. 2012) as a result of global warming.

\section{Conclusions}

Increases in extreme heat events have already been observed across regions of the globe (e.g., Perkins et al. 2012) and a strong increase is projected over the twentyfirst century (Coumou and Robinson 2013), including across southern Australia (Cowan et al. 2014). As such, there is considerable interest in better understanding the potential risk that future increases in heat waves will have on communities. 
(a) SEA anticyclone track

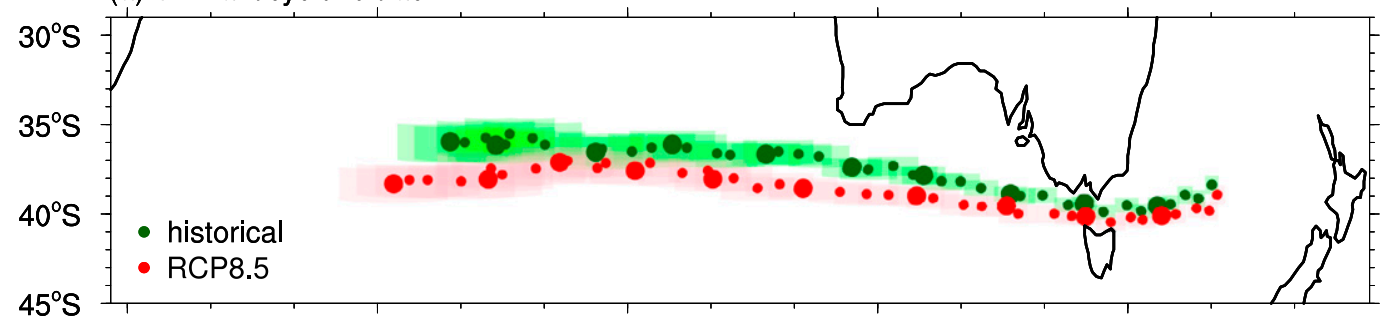

(b) SWA anticyclone track

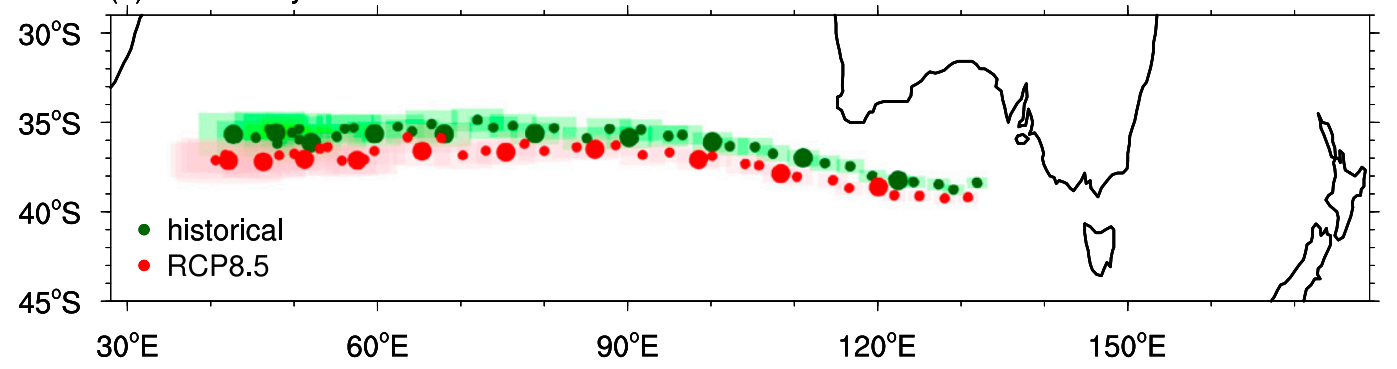

(c) SEA anticyclone central pressure

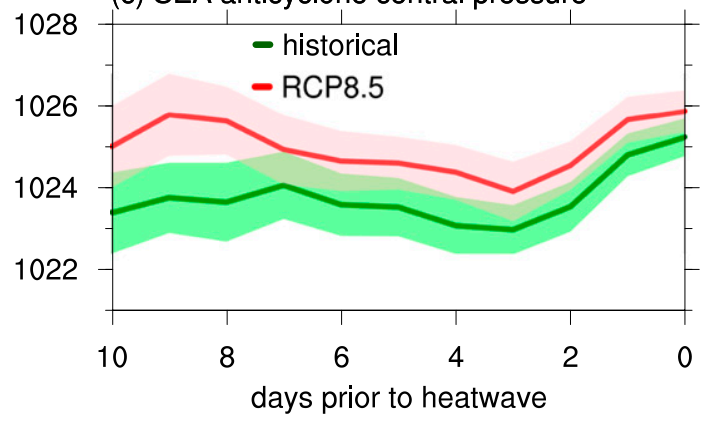

(d) SWA anticyclone central pressure

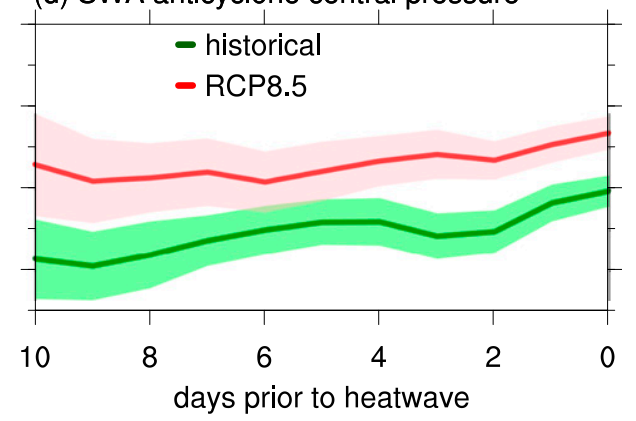

FIG. 16. Multimodel ensemble average anticyclone: (a),(b) tracks and (c),(d) central pressures for the 10 days prior to the start of heat waves in (a),(c) SEA and (b),(d) SWA. Multimodel ensemble averages are based on the heat wave anticyclones from 13 models. Anticyclone properties are shown for the historical simulation over 1950-2005 (green) and for the RCP8.5 simulation over 2045-2100 (red). Shading indicates the 95\% confidence intervals. Every fourth point (larger marker size) represents each day of the track. For the mean central pressures, only every fourth point is plotted to remove diurnal variations in MSLP.

Previous studies have suggested that southern Australian heat waves are strongly associated with feedbacks between SST and atmospheric variability (Sadler et al. 2012; Boschat et al. 2014) and interactions with tropical variability (Parker et al. 2013). However, it is unknown whether future increases in southern Australian heat wave events (e.g., Cowan et al. 2014) can be linked to changes in these precursors. The purpose of this study was 1) to characterize how well the CMIP5 models simulate atmospheric and oceanic conditions associated with heat waves, and 2) to investigate whether projected changes in southern Australian heat waves are due only to changes in the mean-state surface temperature, or are part of a broader dynamical change in atmospheric and oceanic conditions.
To do so, we assessed the ability of CMIP5 models to simulate the atmospheric and oceanic conditions prior to and during southern Australian heat waves. Over 1950-2005, compared to observations, the models simulate $T_{850}$, MSLP, and $Z_{500}$ associated with heat wave events reasonably well. This is demonstrated by high pattern correlation coefficients between observed and model composites of all fields for heat waves in both SEA and SWA.

The models have more difficulty simulating the observed SST patterns associated with heat wave events. This raises questions as to the importance of particular SST patterns leading up to heat waves, as well as the models' ability to simulate such patterns. Based on the models' performance, it is difficult to make inferences 
on the role of SSTs for southern Australian heat waves. This is particularly true for SEA, where none of the models accurately simulates the patterns of SSTs in all key regions considered to be associated with heat wave formation. They most consistently display a highlatitude warming, as reported in Boschat et al. (2014). The models perform better at simulating the SSTs prior to SWA heat waves, particularly the subtropical dipole in the Indian Ocean, despite model biases in the location and spatial extent of pole centers.

In an assessment of the future dynamical changes associated with heat waves, MSLP from the RCP8.5 simulation is compared to the historical simulation. More future SEA heat waves appear to occur with a nonclassical MSLP anticyclone-cyclone couplet pattern, which when combined with warmer mean-state surface temperatures results in an increase in heat wave events across SEA (Cowan et al. 2014). However a subset of heat waves across SEA are associated with a stronger synoptic setup, for which the couplet centers are located slightly farther poleward and are more intense. More notably, some models display a strengthening of the classical synoptic setup associated with SWA heat waves, which raises the possibility that dynamically induced changes may contribute to the larger increase in heat wave events for SWA, compared to SEA.

Furthermore, results from anticyclone tracking suggest that in the future the anticyclones responsible for the hottest southern Australian heat waves will originate from latitudes farther poleward, consistent with the projected poleward shift in the subtropical ridge over Australia. These blocking anticyclones are also projected to strengthen in association with global warming (Timbal et al. 2010).

While CMIP5 models simulate the atmospheric conditions during heat waves reasonably well, their lack of agreement in associated SST patterns suggests that further investigation into the role of the ocean is required. Regional SST patterns preceding and during southern Australian heat waves may provide an explanation as to whether the ocean is a key factor in reinforcing the atmospheric synoptic setup that leads to heat waves. Numerical model experiments whereby local and remote SSTs are perturbed may contribute further to assessing the causality of future changes in heat waves across southern Australia.

Acknowledgments. This research is supported by the Goyder Institute for Water Research and the Australian Climate Change Science Program. A. Pezza acknowledges funding from the Australian Research Council through the Discovery project DP120103950. S. Perkins is supported through the ARC Centre of

Excellence for Climate System Science, CE110001028. We thank Benjamin Ng, Louise Wilson, and two anonymous reviewers for their valuable comments that improved the manuscript. We acknowledge the World Climate Research Programme's Working Group on Coupled Modelling, which is responsible for CMIP, and thank the climate modelling groups (responsible for the models listed in the appendix) for producing and making available their model output.

\section{APPENDIX}

\section{Expansions of CMIP5 Model Names}

ACCESS 1.0

ACCESS 1.3

CanESM2

CNRM-CM5

\section{CSIRO}

$\mathrm{Mk3.6.0}$

GFDL CM3

GFDLESM2G

GFDLESM2M

HadGEM2$\mathrm{CC}$ MIROC-ESM

MIROC-ESMCHEM

MIROC5

MPI-ESM-LR

MRI-CGCM3

NorESM1-M
Australian Community Climate and Earth-System Simulator, version 1.0

Australian Community Climate and Earth-System Simulator, version 1.3 Second Generation Canadian Earth System Model

Centre National de Recherches Météorologiques Coupled Global Climate Model, version 5

Commonwealth Scientific and Industrial Research Organisation Mark 3.6.0

Geophysical Fluid Dynamics Laboratory Climate Model, version 3

Geophysical Fluid Dynamics Laboratory Earth System Model with Generalized Ocean Layer Dynamics (GOLD) component

Geophysical Fluid Dynamics Laboratory Earth System Model with Modular Ocean Model, version 4 (MOM4) component

Hadley Centre Global Environment Model, version 2-Carbon Cycle

Model for Interdisciplinary Research on Climate, Earth System Model

Model for Interdisciplinary Research on Climate, Earth System Model, Chemistry Coupled

Model for Interdisciplinary Research on Climate, version 5

Max Planck Institute Earth System Model, low resolution

Meteorological Research Institute Coupled Atmosphere-Ocean General Circulation Model, version 3

Norwegian Earth System Model, version 1 (intermediate resolution) 


\section{REFERENCES}

Behera, S., and T. Yamagata, 2001: Subtropical SST dipole events in the southern Indian Ocean. Geophys. Res. Lett., 28, 327 330, doi:10.1029/2000GL011451.

Boschat, G., A. B. Pezza, I. Simmonds, S. E. Perkins, T. Cowan, and A. Purich, 2014: Large scale and sub-regional connections in the lead up to summer heat wave and extreme rainfall events in eastern Australia. Climate Dyn., doi:10.1007/ s00382-014-2214-5, in press.

Bracegirdle, T. J., E. Shuckburgh, J.-B. Sallee, Z. Wang, A. J. S. Meijers, N. Bruneau, T. Phillips, and L. J. Wilcox, 2013: Assessment of surface winds over the Atlantic, Indian, and Pacific Ocean sectors of the Southern Ocean in CMIP5 models: Historical bias, forcing response, and state dependence. J. Geophys. Res., 118, 547-562, doi:10.1002/jgrd.50153.

Bureau of Meteorology, 2013: A prolonged autumn heatwave for southeast Australia. Special Climate Statement 45, Australian Bureau of Meteorology, 11 pp. [Available online at http:// www.emknowledge.gov.au/resource/?id=3569.]

Cai, W., P. van Rensch, S. Borlace, and T. Cowan, 2011a: Does the southern annular mode contribute to the persistence of the multidecade-long drought over southwest Western Australia? Geophys. Res. Lett., 38, L14712, doi:10.1029/2011GL047943.

$\longrightarrow,-$, and T. Cowan, 2011b: Influence of global-scale variability on the subtropical ridge over southeast Australia. J. Climate, 24, 6035-6053, doi:10.1175/2011JCLI4149.1.

Carril, A., S. Gualdi, A. Cherchi, and N. Navarra, 2008: Heatwaves in Europe: Areas of homogeneous variability and links with the regional to large-scale atmospheric and SST anomalies. Climate Dyn., 30, 77-98, doi:10.1007/s00382-007-0274-5.

Cassou, C., L. Terray, and A. Phillips, 2005: Tropical Atlantic influence on European heat waves. J. Climate, 18, 2805-2811, doi:10.1175/JCLI3506.1.

Chang, E. K. M., Y. Guo, and X. Xia, 2012: CMIP5 multimodel ensemble projection of storm track change under global warming. J. Geophys. Res., 117, D23118, doi:10.1029/ 2012JD018578.

Coumou, D., and A. Robinson, 2013: Historic and future increase in the global land area affected by monthly heat extremes. Environ. Res. Lett., 8, 034018, doi:10.1088/1748-9326/8/3/034018.

Cowan, T., P. van Rensch, A. Purich, and W. Cai, 2013: The association of tropical and extra-tropical climate modes to atmospheric blocking across southeastern Australia. J. Climate, 26, 7555-7569, doi:10.1175/JCLI-D-12-00781.1.

_ A. Purich, S. Perkins, A. Pezza, G. Boschat, and K. Sadler, 2014: More frequent, longer, and hotter heat waves for Australia in the twenty-first century. J. Climate, 27, 5851-5871, doi:10.1175/JCLI-D-14-00092.1.

Dee, D., and Coauthors, 2011: The ERA-Interim reanalysis: Configuration and performance of the data assimilation system. Quart. J. Roy. Meteor. Soc., 137, 553-597, doi:10.1002/ qj.828.

Della-Marta, P., J. Luterbacher, H. von Weissenfluh, E. Xoplaki, M. Brunet, and H. Wanner, 2007: Summer heat waves over western Europe 1880-2003, their relationship to large-scale forcings and predictability. Climate Dyn., 29, 251-275, doi:10.1007/ s00382-007-0233-1.

Fauchereau, N., S. Trzaska, Y. Richard, P. Roucou, and P. Camberlin, 2003: Sea-surface temperature co-variability in the southern Atlantic and Indian Oceans and its connections with the atmospheric circulation in the Southern Hemisphere. Int. J. Climatol., 23, 663-677, doi:10.1002/joc.905.
Jones, D., W. Wang, and R. Fawcett, 2009: High-quality spatial climate datasets for Australia. Aust. Meteor. Ocean J., 58, 233 248. [Available online at http://www.bom.gov.au/amm/docs/ 2009/jones.pdf.]

Kalnay, E., and Coauthors, 1996: The NCEP/NCAR 40-Year Reanalysis Project. Bull. Amer. Meteor. Soc., 77, 437-471, doi:10.1175/1520-0477(1996)077<0437:TNYRP>2.0.CO;2.

Kent, D., D. Kirono, B. Timbal, and F. Chiew, 2013: Representation of the Australian sub-tropical ridge in the CMIP3 models. Int. J. Climatol., 33, 48-57, doi:10.1002/joc.3406.

Lau, N.-C., and M. J. Nath, 2012: A model study of heat waves over North America: Meteorological aspects and projections for the twenty-first century. J. Climate, 25, 4761-4784, doi:10.1175/ JCLI-D-11-00575.1.

Lewis, S., and D. Karoly, 2013: Anthropogenic contributions to Australia's record summer temperatures of 2013. Geophys. Res. Lett., 40, 3705-3709, doi:10.1002/grl.50673.

Loikith, P., and A. Broccoli, 2014: Variability on the occurrence of winter and summer extreme temperatures over North America. J. Climate, 27, 1600-1618, doi:10.1175/JCLI-D-13-00068.1.

Marshall, A., D. Hudson, M. Wheeler, O. Alves, H. Hendon, M. Pook, and J. Risbey, 2014: Intra-seasonal drivers of extreme heat over Australia in observations and POAMA-2. Climate Dyn., doi:10.1007/s00382-013-2016-1, in press.

Mastrandrea, M., C. Tebaldi, C. Snyder, and S. Schneider, 2011: Current and future impacts of extreme events in California. Climatic Change, 109 (supplement), 43-70, doi:10.1007/ s10584-011-0311-6.

McMichael, A., R. Woodruff, and S. Hales, 2006: Climate change and human health: Present and future risks. Lancet, 367, 859869, doi:10.1016/S0140-6736(06)68079-3.

Meehl, G., and C. Tebaldi, 2004: More intense, more frequent, and longer lasting heat waves in the 21st century. Science, 305, 994 997, doi:10.1126/science.1098704.

Morioka, Y., T. Tozuka, S. Masson, P. Terray, J.-J. Luo, and T. Yamagata, 2012: Subtropical dipole modes simulated in a coupled general circulation model. J. Climate, 25, 4029-4047, doi:10.1175/JCLI-D-11-00396.1.

Murphy, B., and B. Timbal, 2008: A review of recent climate variability and climate change in southeastern Australia. Int. J. Climatol., 28, 859-879, doi:10.1002/joc.1627.

Murray, R., and I. Simmonds, 1991: A numerical scheme for tracking cyclone centres from digital data. Part I: Development and operation of the scheme. Aust. Meteor. Mag., 39, 155-166.

Nairn, J., and R. Fawcett, 2013: Defining heatwaves: Heatwave defined as a heat-impact event servicing all community and business sectors in Australia. CAWCR Tech. Rep. 060, Centre for Australian Weather and Climate Research, $96 \mathrm{pp}$. [Available online at http://www.cawcr.gov.au/publications/ technicalreports/CTR_060.pdf.]

Parker, T. J., G. J. Berry, and M. J. Reeder, 2013: The influence of tropical cyclones on heat waves in southeastern Australia. Geophys. Res. Lett., 40, 6264-6270, doi:10.1002/2013GL058257.

Perkins, S. E., and L. Alexander, 2013: On the measurement of heatwaves. J. Climate, 26, 4500-4517, doi:10.1175/JCLI-D-12-00383.1. - — — , and J. Nairn, 2012: Increasing frequency, intensity and duration of observed global heatwaves and warm spells. Geophys. Res. Lett., 39, L20714, doi:10.1029/2012GL053361.

Pezza, A. B., and T. Ambrizzi, 2003: Variability of Southern Hemisphere cyclone and anticyclone behavior: Further analysis. J. Climate, 16, 1075-1083, doi:10.1175/1520-0442(2003)016<1075: VOSHCA $>2.0 . \mathrm{CO} ; 2$. 
P. van Rensch, and W. Cai, 2012: Severe heat waves in southern Australia: Synoptic climatology and large scale connections. Climate Dyn., 38, 209-224, doi:10.1007/s00382-011-1016-2.

Pui, A., A. Sharma, A. Santoso, and S. Westra, 2012: Impact of the El Niño-Southern Oscillation, Indian Ocean dipole, and southern annular mode on daily to subdaily rainfall characteristics in east Australia. Mon. Wea. Rev., 140, 1665-1682, doi:10.1175/MWR-D-11-00238.1.

Reynolds, R., N. Rayner, T. Smith, D. Stokes, and W. Wang, 2002: An improved in situ and satellite SST analysis for climate. J. Climate, 15, 1609-1625, doi:10.1175/1520-0442(2002)015<1609: AIISAS $>2.0 . \mathrm{CO} ; 2$.

Risbey, J., M. Pook, P. McIntosh, M. Wheeler, and H. Hendon, 2009: On the remote drivers of rainfall variability in Australia. Mon. Wea. Rev., 137, 3233-3253, doi:10.1175/ 2009MWR2861.1.

Sadler, K. J., A. Pezza, and W. Cai, 2012: Cool sea surface temperatures in the Tasman Sea associated with blocking and heatwaves in Melbourne. Bull. Aust. Meteor. Oceanogr. Soc., 25 (5), 80-83. [Available online at http://www.amos.org.au/ documents/item/635.]

Suzuki, R., S. Behera, S. Iizuka, and T. Yamagata, 2004: Indian Ocean subtropical dipole simulated using a coupled general circulation model. J. Geophys. Res., 109, C09001, doi:10.1029/ 2003JC001974.

Timbal, B., and Coauthors, 2010: Understanding the anthropogenic nature of the observed rainfall decline across South Eastern Australia. CAWCR Tech. Rep. 026, Centre for Australian Weather and Climate Research, 202 pp. [Available online at http://www.cawcr.gov.au/publications/technicalreports/ CTR_026.pdf.]
Trenberth, K., and J. Fasullo, 2012: Climate extremes and climate change: The Russian heat wave and other climate extremes of 2010. J. Geophys. Res., 117, D17103, doi:10.1029/2012JD018020.

Ummenhofer, C., and Coauthors, 2011: Indian and Pacific Ocean influences on southeast Australian drought and soil moisture. J. Climate, 24, 1313-1336, doi:10.1175/2010JCLI3475.1.

—, P. McIntosh, M. Pook, and J. Risbey, 2013: Impact of surface forcing on Southern Hemisphere atmospheric blocking in the Australia-New Zealand sector. J. Climate, 26, 8476-8494, doi:10.1175/JCLI-D-12-00860.1.

Unal, Y., E. Tan, and S. Mentes, 2013: Summer heat waves over western Turkey between 1965 and 2006. Theor. Appl. Climatol., 112, 339-350, doi:10.1007/s00704-012-0704-0.

Uotila, P., A. B. Pezza, J. J. Cassano, K. Keay, and A. H. Lynch, 2009: A comparison of low pressure system statistics derived from a high-resolution NWP output and three reanalysis products over the Southern Ocean. J. Geophys. Res., 114, D17105, doi:10.1029/2008JD011583.

Uppala, S., and Coauthors, 2005: The ERA-40 Re-Analysis. Quart. J. Roy. Meteor. Soc., 131, 2961-3012, doi:10.1256/qj.04.176.

Wang, G., D. Dommenget, and C. Frauen, 2014: An evaluation of the CMIP3 and CMIP5 simulations in their skill of simulating the spatial structure of SST variability. Climate Dyn., doi:10.1007/s00382-014-2154-0, in press.

Wheeler, M., H. Hendon, S. Cleland, H. Meinke, and A. Donald, 2009: Impacts of the Madden-Julian oscillation on Australian rainfall and circulation. J. Climate, 22, 1482-1498, doi:10.1175/ 2008JCLI2595.1.

Wilcox, L. J., A. J. Charlton-Perez, and L. J. Gray, 2012: Trends in austral jet position in ensembles of high- and low-top CMIP5 models. J. Geophys. Res., 117, D13115, doi:10.1029/2012JD017597. 